\title{
El primer sistema de alumbrado y balizamiento de costas de Puerto Rico
}

\author{
por \\ Nuria Hinarejos Martín ${ }^{1}$ \\ Universidad Complutense de Madrid
}

\begin{abstract}
El objeto de este artículo es analizar el primer sistema de alumbrado marítimo construido por la Corona española en varios puntos estratégicos del litoral de Puerto Rico e islas adyacentes a mediados del siglo XIX, con el fin de asegurar y desarrollar el comercio y la economía insular, garantizar mayor seguridad a la navegación, reforzar la defensa de los principales puertos comerciales y evitar posibles desembarcos enemigos. El estudio está basado en el análisis de varias fuentes gráficas y documentales custodiadas en el Archivo Histórico Nacional, desconocidas hasta la fecha, las cuales permiten examinar de manera detallada la construcción de cada uno de los faros. Además de contribuir a la aportación de información inédita, acerca de los ingenieros de obras públicas que trabajaron en la isla durante esta centuria, cuya labor ha pasado desapercibida para historiadores y expertos en Arquitectura.
\end{abstract}

Palabras Clave: Puerto Rico; Faros y balizas; Sistema de Defensas; Siglo XIX; Ingenieros de Puertos, Canales y Caminos.

Cómo Citar Este Artículo / Citation: Hinarejos Martín, Nuria, “El primer sistema de alumbrado y balizamiento de costas de Puerto Rico", Revista de Indias, LXXXI/283 (Madrid, 2021): 765-797. https://doi.org/10.3989/revindias.2021.022.

${ }^{1}$ nuriahinarejosmartin@hotmail.com, nuriahinarejos@ucm.es, ORCID iD: https://orcid.org/00000001-7949-2543

Copyright: (C) 2021 CSIC. Este es un artículo de acceso abierto distribuido bajo los términos de una licencia de uso y distribución Creative Commons Reconocimiento 4.0 Internacional (CC BY 4.0). 


\section{INTRODUCCIÓN}

Puerto Rico es la isla más oriental y la de menor extensión de las Antillas Mayores, fue una posesión española de gran valor estratégico en el Caribe por su proximidad a Cuba y República Dominicana. Las ventajas que ofrecía la bahía y el puerto de San Juan, capital de la isla, la convirtieron en escala de la «Carrera de Indias». Circunstancias que obligaron a la Corona española a invertir grandes recursos en la construcción de un complejo sistema defensivo para proteger la isla de las principales potencias europeas, que vieron en ella una importante fuente de riquezas. Las primeras defensas realizadas en la ciudad de San Juan, capital de la isla, fueron erigidas a mediados del siglo XVI, aunque el sistema defensivo de Puerto Rico no quedó concluido hasta finales de 1898, cuando la isla pasó a manos del gobierno de Estados Unidos tras la derrota española en la Guerra Hispanoamericana ${ }^{2}$. Durante casi cuatrocientos años se construyeron nuevas fortificaciones y se reformaron las existentes, con el fin de adaptarlas al modelo de arquitectura abaluartada desarrollado en Francia por el mariscal de campo Sebastién Le Pestre de Vauban y a las teorías modernas de los ingenieros franceses Charles Forbes René de Montalembert, Lázare Carnot y Françóis Haxo, como consecuencia de la evolución experimentada en la artillería y las necesidades tácticos-estratégicas del momento.

A mediados del siglo XIX Puerto Rico experimentó un importante crecimiento económico y demográfico como consecuencia de la explotación de los cultivos de caña de azúcar y café. Ello obligó a la Monarquía Hispana a invertir importantes recursos en la construcción de numerosas baterías costeras en los principales puertos comerciales, para evitar posibles desembarcos enemigos, proteger la economía y el comercio insular y eliminar el comercio ilícito ${ }^{3}$. Durante esta centuria se proyectaron, además, numerosas obras públicas y se realizaron importantes mejoras en el sistema de comunicaciones siguiendo los modelos empleados en Cuba. En 1831 se construyó una carretera pavimentada en la ciudad de Ponce, que fue la principal productora azucarera; una Real Orden de 1838 obligó a todos los habitantes a trabajar en la construcción de una red de caminos para favorecer el desarrollo comercial y económico de la isla, cuyas obras fueron dirigidas por una Comisión Directiva de Canales y Puertos, en la que trabajaron varios ingenieros de Obras Públicas entre los que destaca-

\footnotetext{
${ }^{2}$ Hinarejos Martín, 2020a.

3 Idem.
} 


\section{ron César Llorens ${ }^{4}$, Evaristo Churruca ${ }^{5}$, Miguel Martínez Campos y Leo- nardo de Tejada ${ }^{6}$, entre otros.}

${ }^{4}$ Desconocemos la fecha y lugar de su nacimiento, así como cualquier otra información acerca de su vida personal puesto que no aparece mencionada en su expediente. El 24 de noviembre de 1886 fue destinado a Puerto Rico con el grado de ingeniero jefe de primera clase, un sueldo de 1.800 pesos y 5.200 de sobresueldo, aunque según consta en varios informes médicos padecía una gastroenteritis crónica que le impidió viajar en ese momento. Embarcó en Cádiz el 15 de febrero a bordo del vapor correo Antonio López, capitaneado por José Malcampo y Monge y tomó posesión de su cargo el 2 de marzo. Permaneció en la isla poco menos de un año, ya que el 20 de enero de 1868 solicitó su regreso a la Península con motivo de su quebrantado estado de su salud, solicitud que fue aprobada en marzo de ese mismo año, aunque desconocemos la fecha exacta en la que abandonó Puerto Rico. El último dato que conocemos de este ingeniero es que desembarcó en Southampton (Inglaterra) procedente de la isla de Saint Tomas en el vapor británico Douro (28 de mayo de 1868), arribó a la península el 30 de junio y fue destinado a la División de Ferrocarriles del Norte para verificar la tasación del ferrocarril de Isabel II junto al ingeniero Manuel Peironcel. Expediente personal de César Llorens y Ceriola, Archivo Histórico Nacional, Madrid (AHN), Ultramar, 314, exp. 7. Varios ingenieros pasan de la península a trabajar a la isla, AHN, Ultramar, 425, exp. 22. "Notas Varias", 1868.

${ }^{5}$ Sáenz Ridruejo afirma que Evaristo Churruca era oriundo de Motrico (Guipúzcoa), hijo de un diputado y senador del País Vasco, finalizó su formación como ingeniero de Caminos, Canales y Puertos en 1863. Permaneció dos años en el levante español donde dirigió la construcción del faro de Portman en La Unión, y los faros de Cabo de Palos y Punta de Podadera en Cartagena (Murcia). También realizó el anteproyecto de la carretera de Calasparra a Murcia. En 1865 pasó a Valencia para analizar las avenidas del Júcar y un año después, junto a César Llorens, solicitó permiso para trabajar en Puerto Rico con el grado de ingeniero jefe de segunda clase. Embarcó en Cádiz (30 de diciembre de 1866) y permaneció en la isla siete años, durante los cuales, fue nombrado ingeniero jefe del distrito oriental, en 1870 fue ascendido a ingeniero inspector de Obras Públicas con un sueldo de 4.500 pesos y 13.000 de sobresueldo y recibió la encomienda de la Orden de Isabel la Católica. Construyó los puentes de Bayamón, Caguas y Mayagüez, reconstruyó varios edificios tras el terremoto de 1867 y proyectó el faro del castillo de San Felipe del Morro. Solicitó su relevo tras cumplir los seis años de servicio reglamentarios en Ultramar (2 de noviembre de 1872), siendo sustituido por Leonardo de Tejada (28 de enero de 1873). Embarcó en el vapor Isla de Cuba con destino a La Habana, capitaneado por Pedro González y Valerio. El mismo autor afirma que durante su estancia en Puerto Rico enfermó de fiebre amarilla y tras abandonar la isla fue destinado a Estados Unidos, para visitar el sistema de abastecimiento de agua de Chicago. Escribió varias memorias técnicas hasta que a finales de 1874 ingresó en la Junta Consultiva de Caminos, Canales y Puertos de Madrid y tres años después fue nombrado facultativo del puerto de Bilbao, donde trabajó durante más de treinta años en la construcción de un proyecto de mejora de la barra y encauzamiento de la mitad inferior de la ría, labor por la que obtuvo el título de conde de Motrico. Inmaculada Cierva afirma que falleció en Bilbao en 1917. Varios ingenieros pasan de la península a trabajar a la isla, AHN, Ultramar, 425, exp. 22. Expediente personal de Evaristo Churruca y Brunets, AHN, Ultramar, 320, exp. 2. Churruca, 1883: 6-840. Sáenz Ridruejo, 2009: 320. Aguilar Civera, 2012.

${ }^{6}$ Nació en Málaga el 8 de enero de 1838, se formó como ingeniero de Caminos y en 1861 fue destinado a Murcia donde proyectó varios faros. En junio del año siguiente, se des- 
Se realizaron varias redes de abastecimiento de aguas; se levantaron algunos puentes metálicos; se construyó un muelle de madera en la bahía de San Juan para facilitar el abastecimiento de víveres y el transporte tropas a San Juan; se proyectaron varias obras de mejora en los puentes de San Antonio y Martín Peña para facilitar la comunicación de la capital; se construyó una carretera de 51 kilómetros de largo que comunicaba los municipios de Caguas y San Juan, cuyas obras se prolongaron hasta 1857; se mejoró la red de comunicaciones con la construcción de un tranvía que unía los municipios de Río Piedras y San Juan; se instauró un sistema de lanchas de vapor para facilitar el tránsito de la capital con el municipio de Cataño. En 1859 se empleó por primera vez el telégrafo en la isla y se aprobó el Primer Plan de Carreteras de Puerto Rico con una vía principal que comunicaba las ciudades de Ponce y San Juan, pasando por los municipios de Río Piedras, Caguas, Cayey, Aibonito, Coamo y Juana Díaz, complementada con un sistema de carreteras secundarias. Luis Pumarada y María de los Ángeles Castro, afirman que en 1872 la isla sólo contaba con 48 kilómetros de carreteras pavimentadas, lo que obligó a Amadeo I a invertir cuantiosos recursos en la construcción de nuevas redes de comunicación ${ }^{7}$. Tres años después se construyó el primer tramo de la Carretera Central que unía los municipios de Caguas y Cayey, cuyas obras no quedaron concluidas hasta 1881. Esta carretera tuvo una finalidad política, económica y defensiva puesto que unía los principales puertos comerciales de la isla, por lo que su defensa se reforzó con varios puentes de ladrillo y otros de hierro procedente del continente europeo, sostenidos por pilastras de hormigón. Esta carrera se convirtió en el objetivo de las tropas norteamericanas durante el ataque del 25 de julio de 1898, ya que tras desembarcar en los puertos de Guánica, Ponce y Arroyo, todos ellos situados al

plazó a Madrid para analizar los proyectos de los ferrocarriles que unían las ciudades de Murcia y Granada y Albacete y Jaén. A su llegada a Puerto Rico, Tejada y Evaristo Churruca realizaron un reconocimiento a las carreteras de Caguas y Bayamón y en 1876 redactó una memoria sobre los ferrocarriles de la isla. Las diferencias con el gobernador le obligaron a desplazarse a Cuba como ingeniero jefe de Obras Públicas. Durante su estancia en La Habana proyectó el Plan General de Alumbrado Marítimo y una memoria detallada de las obras públicas realizadas en la isla entre 1873 y 1883. En 1884 regresó a la Península donde fue ascendido a jefe del negociado de Obras Públicas del Ministerio de Ultramar; diez años después ingresó en la sección de carreteras de la Junta Consultiva de Caminos, Canales y Puertos. En 1898 fue ascendido a inspector y vocal de la junta; un año después fue elegido presidente de la Comisión Central del Cuerpo de Ingenieros de Caminos y de la Revista de Obras Públicas y durante dos años (1900-1902) ocupó el cargo de director de la Escuela de Caminos, Canales y Puertos. Falleció en Madrid en octubre de 1927. Lugo-Viña, 1890: 21. Sáenz Ridruejo, 2009: 322.

7 Pumarada y Castro, 1996: 4. 
sur de Puerto Rico, las tropas enemigas avanzaron hacia la capital para tomar la ciudad y bloquear el puerto y la bahía de San Juan.

En 1880 se aprobó el Plan General de Ferrocarril para facilitar la comunicación de la ciudad de Ponce, que era el segundo puerto comercial de la isla, con la capital. Sus obras comenzaron el 15 de octubre de 1888, convirtiéndose en una vía de comunicación fundamental para el desarrollo de la producción azucarera hasta su desaparición en 1953.

\section{APROBACIÓN DEL PRIMER SISTEMA DE ALUMBRADO MARÍTIMO}

En este contexto, la Corona española invirtió importantes recursos técnicos y económicos en la definición y construcción del Primer Plan de Alumbrado y Balizamiento de costas de la isla, elaborado el 26 de febrero de 1869 por el ingeniero jefe de Obras Públicas, Miguel Martínez Campos ${ }^{8}$. Este proyec-

${ }^{8}$ Se formó como ingeniero de Caminos, Canales y Puertos en 1860 y realizó varios proyectos para la construcción de algunos puentes y carreteras en la ciudad de Cáceres, labor por la que fue ascendido a ingeniero de primera clase e Inspector General de Obras Públicas de Puerto Rico (14 de octubre de 1866). Embarcó en Cádiz (30 de noviembre) y durante los tres años que permaneció en la isla redactó un proyecto para la construcción del puerto de San Juan (el primer proyecto de alumbrado marítimo), y un plan de carreteras y caminos, además de diseñar dos puentes de hierro y uno de mampostería, entre los que destacó el puente metálico de los Reyes Católicos erigido en 1876 sobre el río Toa, actual río de La Plata. El 10 de enero de 1867 reclamó 3.486 escudos y 300 maravedís devengados de los costes del viaje, solicitud que fue desestimada y el 9 de febrero solicitó su regreso a la Península debido al quebrantado estado de salud de su esposa y uno de sus hijos. Es posible pensar que dicha solicitud tampoco fuera aprobada, puesto que según consta en su expediente personal el 3 de marzo de ese mismo año fue nombrado Director de Obras Públicas e ingeniero jefe de segunda clase, con un sueldo de 2.400 escudos y 7.600 de sobresueldo. Desconocemos la fecha exacta en la que abandonó la isla, pero según consta en su expediente arribó a Cádiz el 16 de mayo de 1869 y reclamó una indemnización de 348 escudos y 300 maravedís. El 12 de septiembre de 1869 fue nombrado profesor de la Escuela de Ingenieros de Caminos, Canales y Puertos donde impartió las asignaturas de «aplicaciones de la hidráulica» y «construcción en general». Sáenz Ridruejo afirma que entre 1873-1876 se ocupó de la secretaría del centro e interrumpió su labor docente para dirigir la construcción del ferrocarril que unía las ciudades extremeñas de Malpartida y Cáceres. Tres años después fue nombrado académico de Ciencias, aunque desconocemos el motivo por el que no llegó a tomar posesión del nombramiento. En 1886 ingresó en el Consejo de Estado donde permaneció hasta el 30 de septiembre de 1889, cuando se convirtió en administrador de la Compañía de Ferrocarriles de Madrid, Zaragoza y Alicante de la que más tarde fue director general, vicepresidente del Consejo de Administración y miembro del Comité de Dirección. En noviembre de 1890 terminó sus estudios de derecho y se convirtió en Diputado de la ciudad de Matanzas (Cuba), representó a los municipios puertorriqueños de Aguadilla y Guayama en el Congreso y en octubre de 1899 obtuvo 
to fue aprobado por el Ministerio de Fomento y la Comisión Central de Faros, formada por varios oficiales de la Armada y Caminos, presidida por el director de Obras Públicas9. Esta institución se fundó el 6 de enero de 1860 bajo la administración de la Comisión de Faros de la Península, creada el 4 de enero de 1842 durante la regencia de Baldomero Espartero, cuya finalidad era definir y establecer las ayudas necesarias a la navegación de las costas españolas, a la que siguió una disposición del 13 de abril del mismo año.

Miguel Martínez Campos elaboró un estudio basado en la construcción de catorce faros emplazados en puntos estratégicos del litoral de Puerto Rico, para reforzar el sistema defensivo construido hasta el momento en la isla ${ }^{10}$. Proyecto que no ha sido mencionado hasta el momento, y el autor lo acompañó de un plano y un presupuesto valorado en 285.000 escudos y 33.450 más, correspondientes a los sueldos de 14 torreros principales, 11 ordinarios y 7 auxiliares, encargados de su mantenimiento ${ }^{11}$, cuyos costes anuales estimó

el cargo vitalicio de senador que desempeñó hasta 1905. Fue recompensado con la cruz de María Victoria y la Gran Cruz de Alfonso XII por los servicios prestados en el Ministerio de Fomento. Falleció el 20 de noviembre de 1906 tras sufrir una ceguera que le apartó de su carrera política y profesional. Expediente personal de Miguel Martínez Campos, AHN, Ultramar, 317, exp. 2. Nombran ingeniero jefe de la Comisión de faros, AHN, Ultramar, 409, exp. 15. Sáenz Ridruejo, 2009: 311-342.

9 En 1847 se creó el Ministerio de Comercio, Instrucción y Obras Públicas y la Comisión Central de Faros, pasó a depender de la Dirección General de Obras Públicas. Esta comisión fue la encargada de presentar el Plan General de Alumbrado Maritimo de las Costas y Puertos de España e Islas Adyacentes. Cuatro años después este Ministerio se hizo cargo de la administración de los puertos, que hasta ese momento dependían del Ministerio de Marina, pasando a denominarse Ministerio de Fomento. En 1872 se creó el Depósito Central de Faros, bajo la inspección de la Comisión de Faros, cuya finalidad era facilitar los enseres, útiles y efectos necesarios que no pudieran adquirirse en las respectivas provincias, reunir los datos estadísticos necesarios para ejercer la vigilancia y realizar un buen servicio, además de redactar los proyectos de construcción y reforma de los faros, formar a los alumnos de la Escuela de Caminos, Canales y Puertos y ayudar a la instrucción del Cuerpo de Torreros. Sin embargo, las competencias de este Depósito Central no duraron mucho tiempo, ya que en 1899 fue sustituido por la Inspección Central de Señales Marítimas dependiente de la Comisión de Faros y la Junta Consultiva de Caminos, Canales y Puertos, instituciones que en 1907 fueron consignadas como Comisión Permanente de Faros y Consejo de Obras Públicas, cuya labor era coordinar y desarrollar cualquier actividad relacionada con la navegación estatal.

${ }^{10}$ Este proyecto de alumbrado ha sido mencionado por varios autores puertorriqueños entre los que destacan José Antonio Mari Mut, Norma Castaldi y Carolina E. Santiago, entre otros, aunque ninguno de ellos parece haber consultado la documentación relacionada con la construcción de dichos faros, custodiada en el Archivo Histórico Nacional de Madrid.

${ }^{11}$ El 17 de marzo de 1882 se aprobó el Reglamento para la Organización y Servicio de Torreros de Faros de la Isla de Puerto Rico, en el que se establecieron tres clases de torreros: principal, segundo y tercero con un sueldo de 500, 400 y 300 pesos anuales. Pertenecían al 
en 48.000 escudos. En ese momento la isla sólo contaba con un faro emplazado en el castillo de San Felipe del Morro, que servía de referencia a las ciudades de Arecibo situada en el extremo noroeste de la isla y Fajardo en la costa oriental ${ }^{12}$.

\section{Figura 1. Plan de Alumbrado Marítimo de la isla de Puerto Rico}

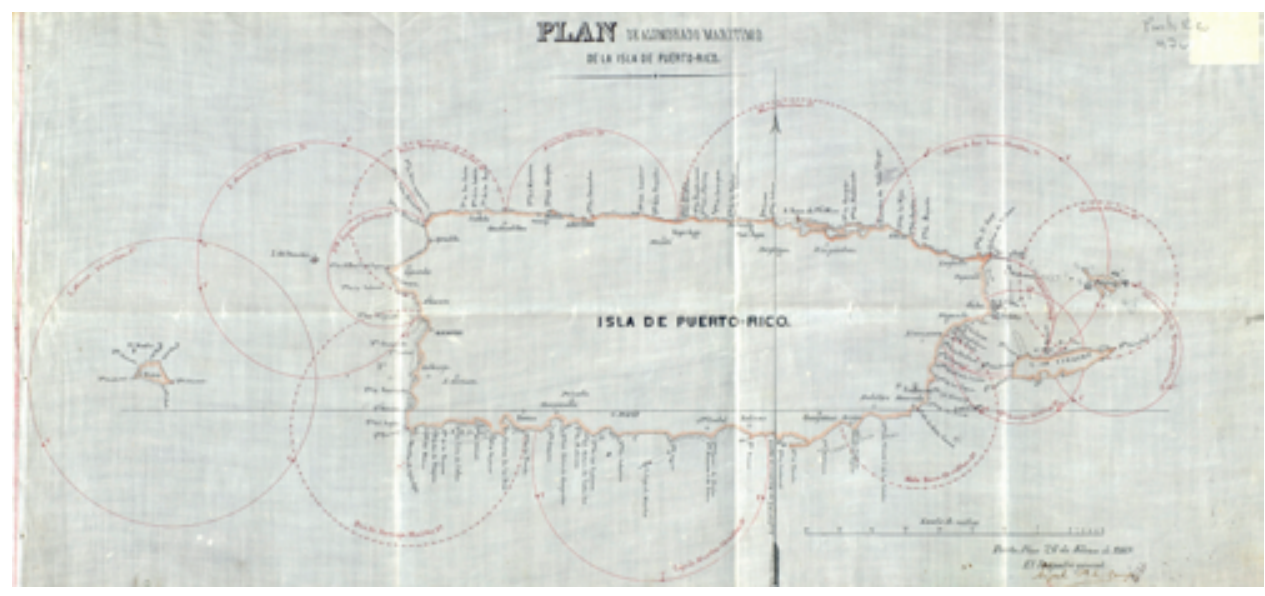

Fuente: Archivo Histórico Nacional, Madrid (AHN), Ultramar, Mapas Planos y Dibujos (MPD), 974.

Todos los faros fueron diseñados siguiendo el modelo tipológico imperante en Francia, caracterizado por una forma y disposición de tipo clásico, cubiertas planas de azotea compuestas por vigas y alfarjías de madera de ausubo abun-

cuerpo de Torreros creado el 21 de mayo de 1851, cuya denominación se mantuvo vigente hasta 1939 cuando fueron consignados técnicos mecánicos de señales marítimas. Una Real Orden del 5 de junio de 1851 determinó una formación reglada, el uso de uniforme y armamento, formado por una carabina corta con canana y municiones para 20 tiros. Fueron los encargos de mantener en buen estado el faro; vigilar los mecanismos y combustible; realizar una limpieza exhaustiva de la óptica, linterna y edificio; y cumplimentar la documentación relativa a observaciones meteorológicas y dirección de los vientos. Dependiendo de la importancia y el grado de aislamiento del faro, el número de torreros variaba de uno a tres. La implantación de los sistemas automáticos hizo que esta profesión se declarara a extinguir en la Ley 27/1992 del 24 de noviembre de Puertos del Estado y de la Marina Mercante. Sánchez Beitia, 2017.

12 En marzo de 1894 Puerto Rico contaba con 11 faros y en el ataque estadounidense existían 13 en funcionamiento y tres en construcción: los faros de Mona, Puerto Ferro y Arecibo. Sánchez Terry, 1992: 169. 
dante en la isla, fachadas dotadas de cornisas pronunciadas, vanos rectangulares y torres de planta circular ligeramente troncocónica rematadas con cornisas, sobre las que se construyó un torreón para sustentar la linterna. Fueron edificios de mampostería con muros gruesos compuestos de piedra caliza, arena, mortero hidráulico y cal, dando como resultado construcciones resistentes a los frecuentes huracanes y terremotos del Caribe. Todos ellos tenían planta rectangular con dos crujías longitudinales y dos transversales, dotadas de un vestíbulo, gabinete de ingenieros, almacén, una torre cuya altura variaba en función del lugar elegido para su emplazamiento y el alcance necesario de la luz. También debía tenerse en cuenta la fuerza del viento y el envite del oleaje y su forma variaba, aunque las más habituales debido a su resistencia fueron de fuste troncopiramidal de varias caras, cilíndricas o troncocónicas, de sección circular, cuyo diámetro decrecía con la altura de la torre.

Estos edificios contaban con un depósito de petróleo, cuarto de lejías, habitaciones de los torreros formadas por una sala, dormitorios, escusado y cocina con fogones de hierro adquiridos en Nueva York y un fregadero de hierro esmaltado; una escalera de caracol de hierro fundido que conducía a la «cámara de servicio», donde los torreros realizaban sus turnos y las funciones necesarias de mantenimiento, y un aljibe de planta cuadrada cubierto con bóveda de ladrillo, para recoger las aguas pluviales. La vivienda de los torreros debía estar conectada con el lugar de trabajo y esto provocó una distribución interior peculiar, ya que todas las estancias estaban comunicadas por un vestíbulo donde convergían las viviendas, almacenes, despacho de la documentación y las dependencias de inspección, que ocupaban los ingenieros en las visitas que realizaban a los faros. En algunos casos, las cocinas, letrinas y almacenes estaban ubicados en dependencias exteriores y los vestíbulos frente a la entrada de la torre, pero nunca estaban conectados directamente con las viviendas.

El mobiliario era muy sencillo y económico ya que contaban con lo indispensable para facilitar el alojamiento de los torreros. En cuanto a los materiales empleados en su construcción, destacó la mampostería y el ladrillo en la edificación de los muros; ladrillo para los elementos que debían llevar aristas vivas, tales como el basamento, zócalo, aristones y jambas; sillería para los arcos de las puertas y ventanas, bóvedas de la torre y aljibe; madera de ausubo propia del país para las puertas, ventanas, vigas y alfarjías de las cubiertas y madera de pichipén también abundante en la isla, para toda la obra de carpintería de taller; cubiertas de azotea reforzadas con vigas y alfarjías de madera, protegidas por tres capas de ladrillo adherida con una argamasa de cal, arena y agua y una última capa de ladrillo cubierta de brea o alquitrán para impermeabilizar el interior de las estancias; losas de Génova y Canarias para el pavimento del 
almacén, cocinas, letrinas, pasillo, vestíbulo y la base de la torre; madera de pichipén para evitar la humedad en las habitaciones de los torreros y cemento de Portland en el almacén de combustible y la sala de lejías ${ }^{13}$.

La decoración de los edificios fue muy sencilla y austera, los vanos fueron realizados con arreglo a las leyes de simetría, los dos cuerpos centrales estaban ligeramente resaltados sobre el resto de las fachadas longitudinales y la línea de sombras producida por las salientes y las disposiciones de su fábrica. Las únicas diferencias notables corresponden a su estética, ya que el ingeniero encargado de la obra determinaba el color empleado en la fachada y las torres podían ser de planta cuadrada, hexagonal u octogonal. Estaban emplazadas en el punto central del edificio o en la fachada posterior, y rematadas por linternas metálicas poligonales o cilíndricas que albergaban el sistema óptico y la lámpara. Las linternas fueron construidas siguiendo el modelo francés, basado en la construcción de una cúpula y cupulino esféricos con montantes verticales y zócalo de fábrica, decoradas con balaustradas de hierro y dotadas de vidrieras, que evitaban la entrada del viento y el polvo al interior del edificio y protegían las lentes Fresnel ${ }^{14}$, formadas por elementos catadióptricos o elementos dióptricos, adquiridas por el ingeniero de Obras Públicas, José Echevarría, comisionado en París para la compra de material marítimo ${ }^{15}$.

${ }_{13}$ Desde mediados del siglo XIX Puerto Rico importó cemento de Portland procedente de varios países europeos como Alemania, Bélgica y Dinamarca y fue empleado por primera vez en la isla en la pavimentación de las calles de Ponce. Este material se caracterizó por su reducido coste y buena calidad. Era importado en barriles impermeables de 376 libras y no requería ninguna preparación previa. Según indica la arquitecta puertorriqueña Cueto, este material fue utilizado en la construcción de numerosas carreteras, edificios civiles y religiosos a finales del siglo XIX y comienzos del XX. Beatriz de Cueto, "La luz al final del viaje: el Faro de las Cabezas de San Juan", Diario El Nuevo Día, sin fecha: 12-16, https://construccionelnuevodia.com/noticia/ la-luz-al-final-del-viaje-el-faro-de-las-cabezas-de-san-juan/

14 Estas lentes fueron creadas por el ingeniero de Caminos, Canales y Puertos, Augustin Jean Fresnel. Durante toda su carrera profesional realizó numerosas investigaciones ópticas por las que recibió el premio de la Real Academia de las Ciencias en 1819. Diseñó una lente escalonada que supuso un avance considerable en los sistemas reflectores marítimos, realizó varios descubrimientos relacionados con las aplicaciones ópticas destinadas a mejorar los faros y publicó Memorias sobre un nuevo sistema de iluminación para los faros, donde expuso sus hallazgos sobre las lentes escalonadas, sus experiencias sobre las lámparas de mechas múltiples y su proyecto de faro giratorio lenticular para el faro de Cordouan. Fue nombrado ingeniero jefe del Servicio Central de Faros y Balizas (1 de junio de 1824), cargo que desempeñó hasta su fallecimiento el 14 de julio de 1827.

${ }^{15}$ Ingeniero de Caminos comisionado en París desde el 25 de febrero de 1864, para la adquisición de los aparatos de todos los faros de las posesiones españolas de Ultramar, dado que la tecnología francesa era puntera hasta que fue desplazada por la competencia británica de la casa Chace Brothers a comienzos del siglo XX. En 1869 José Echevarría propuso ad- 
Figura 2. Proyecto del faro de 3er orden de la isLa de CAJA DE MUertos: HoJa 3. ${ }^{a}$ : Planta, alZados Y SECCIONES GENERALES DEL EDIFICIO Y TORRE



Fuente: AHN, Ultramar, MPD, 1088.

En el Primer Plan de Alumbrado y Balizamiento de costas de la isla, fechado el 26 de febrero de 1869, Miguel Martínez Campos preveía la construcción de un faro de $2 .^{\circ}$ orden en la isla de Mona, situada a 80 kilómetros al oeste de Mayagüez y a 193 kilómetros de la capital; además de los faros de $3 .^{\circ}$ orden de Arecibo, a 80 kilómetros al noroeste de la capital, Arroyo, a casi 100 kilómetros al sureste de San Juan, Cabezas de San Juan en el puerto de Fajardo, situado a 75 kilómetros de la capital, los Morrillos de Cabo Rojo, al suroeste de la isla y a 197 kilómetros de la capital, el de la isla de Caja de Muertos, en el Caribe y a 16 kilómetros de Ponce, y el faro del castillo de San Felipe del Morro en el extremo occidental de la isleta de San Juan. También tenía previsto la construcción de los faros de $4 .^{\circ}$ orden de Punta Boriquen en el municipio de Aguadilla,

quirir un tren a la Société Nouvelle des Forges et Chatiers de la Méditerranée, encargada de la construcción de la mayor parte del material empleado en los trabajos marítimos del canal de Suez, para realizar una limpieza de la bahía de San Juan, cuyos costes estimó en 259.398,260 escudos. Adquisición de aparatos para faros para las provincias de Cuba, Puerto Rico y Filipinas, AHN, Ultramar, 228, exp. 17. Expediente relativo al faro del Morro de San Juan, AHN, Ultramar, 409, exp. 15. Echevarría Elguero, 1869: 154-156. 
a unos 130 kilómetros al oeste de la capital, el faro de isla Culebra, a 87 kilómetros al este de Puerto Rico, y otro en Maunabo situado al sureste de la isla y a 83 kilómetros de San Juan, además de dos faros de $5 .^{\circ}$ orden en el puerto de Punta de Mulas de la isla de Vieques, emplazada a unos 32 kilómetros al este de Fajardo y a 96 kilómetros de la capital, y el faro de Ceiba, a 66 kilómetros al oeste de San Juan y poco menos de 8 kilómetros de Fajardo. Completan la serie de faros previstos por Martínez Campos en el plan dos faros de $6 .^{\circ}$ orden en Aguada, a 150 kilómetros al noreste de San Juan, y en el puerto de Guánica, situado al suroeste de Puerto Rico y a 160 kilómetros de la capital.

Figura 3. Faro de $5 .^{\circ}$ orden de Puerto Ferro: Hoja n. ${ }^{o}$ 2: Plantas

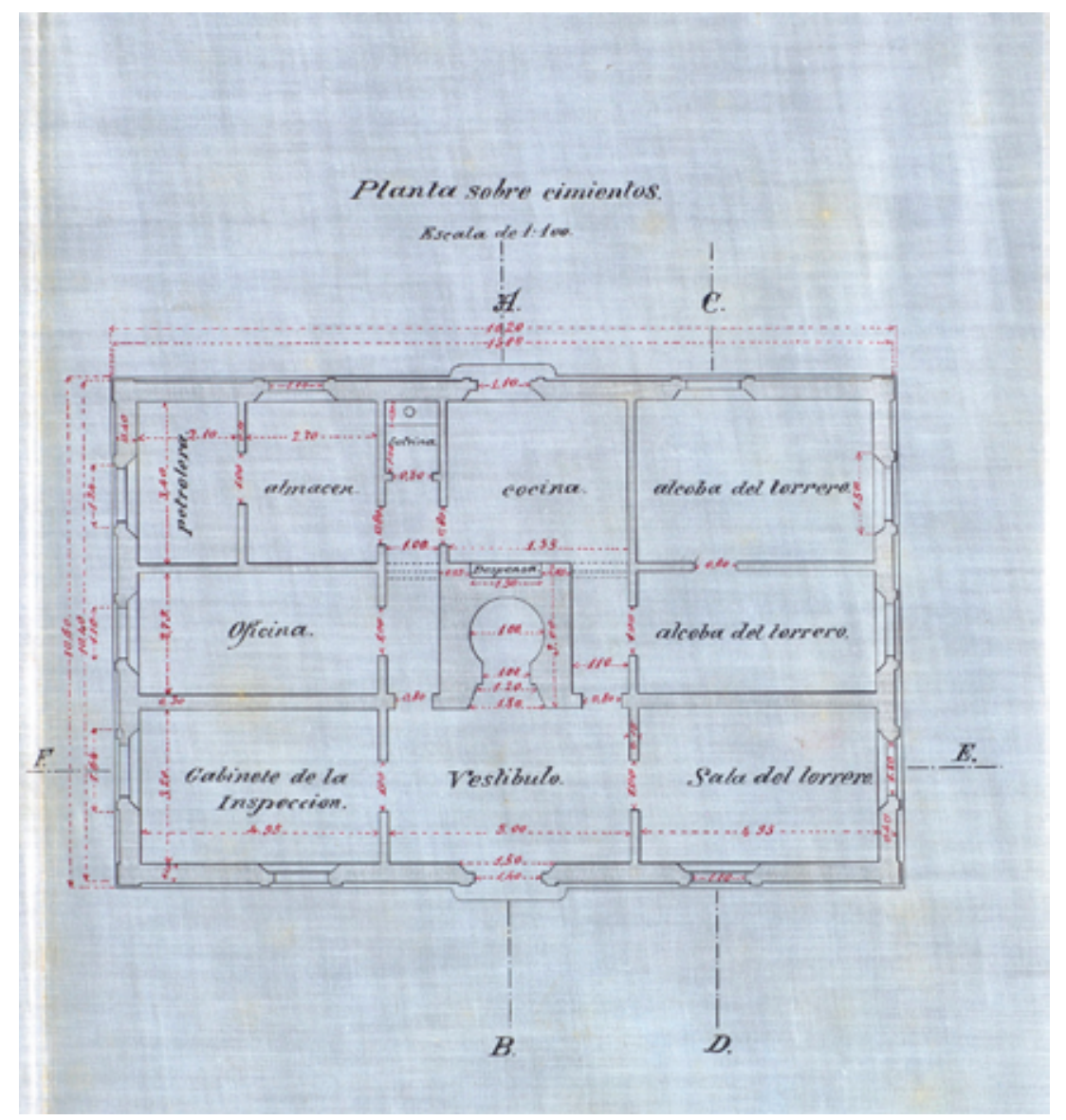

Fuente: AHN, Ultramar, MPD, 1077. 
Figura 4. CRoQuis de La isla de Puerto Rico expresivo de LOS DIVERSOS PlaNeS DE VÍAS DE COMUNICACIÓN Y DE ALUMBRADO MARÍTIMO, VIGENTES EN EL MES DE LA FECHA

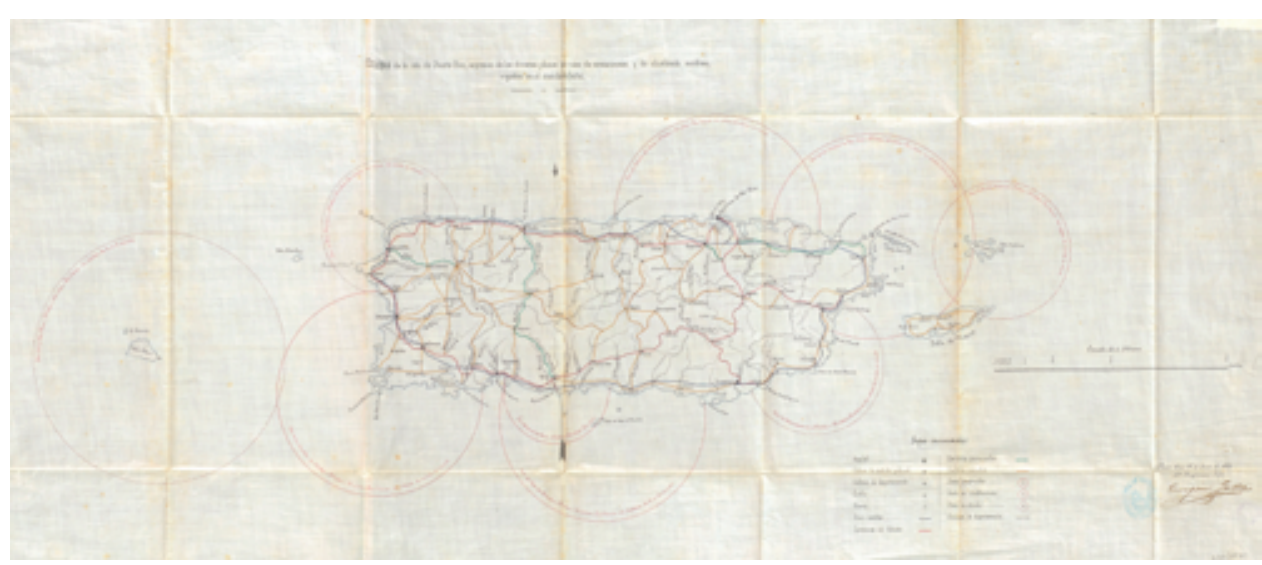

Fuente: AHN, Ultramar, MPD, 489.

Los seis órdenes de clasificación de los faros se corresponden con las características constructivas del propio faro, su uso y el sistema de lentes utilizado, ya que el tamaño de estas determina la distancia focal e intensidad lumínica, cuyo alcance oscilaba entre las 5 y las 18 millas náuticas según indica el siguiente cuadro.

FIGURA 5

\begin{tabular}{|c|c|c|c|c|}
\hline Tipo & Altura de lentes & $\begin{array}{c}\text { Distancia útil } \\
\text { (millas) }\end{array}$ & Distancia focal & Tipo general de uso \\
\hline $1^{\circ}$ & - & 20 & - & $\begin{array}{c}\text { Recaladas avisando de la } \\
\text { proximidad a tierra }\end{array}$ \\
\hline $2^{\circ}$ & $81.46^{\prime}-206.9 \mathrm{~mm}$ & 18 & $27.6^{\prime}-70.10 \mathrm{~mm}$ & $\begin{array}{c}\text { Ayudan a marcar cabos, bahías, } \\
\text { arrecifes, disminución de la } \\
\text { profundidad }\end{array}$ \\
\hline $3^{\circ}$ & $62.05^{\prime}-57.61 \mathrm{~mm}$ & 15 & $19.7^{\prime}-50.04 \mathrm{~mm}$ & $\begin{array}{c}\text { Localizan grandes bahías, } \\
\text { desembocaduras de ríos, canales, } \\
\text { grandes lagos }\end{array}$ \\
\hline $4^{\circ}$ & $28.43^{\prime}-72.21 \mathrm{~mm}$ & 10 & $9.8^{\prime}-24.89 \mathrm{~m} 7.4^{\prime}-$ & $\begin{array}{c}\text { Dirección de entradas a puertos } \\
\text { y bahías }\end{array}$ \\
\hline $5^{\circ}$ & $21.3^{\prime}-54.10 \mathrm{~mm}$ & 9 & $7.4^{\prime}-18.80 \mathrm{~mm}$ & $\begin{array}{c}\text { Recaladas avisando de la } \\
\text { proximidad a tierra }\end{array}$ \\
\hline $6^{\circ}$ & $17.05^{\prime}-43.31 \mathrm{~mm}$ & 5 & $5.9^{\prime}-14.99 \mathrm{~mm}$ & Lagos y puertos \\
\hline
\end{tabular}

Fuente: Gráfico extraído de http://vagamundos.com/faros-del-mundo/informacion/tipos-de-faros/ 
Este proyecto de alumbrado fue modificado el 3 de abril de 1886 por Enrique $\mathrm{Gadea}^{16}$, presidente de la Comisión Mixta de Marina y Obras Públicas, en una junta a la que acudieron los ingenieros Manuel Maese Pérez y Rafael Rávena ${ }^{17}$.

\section{FAROS CONSTRUIDOS EN LA COSTA ATLÁNTICA}

A mediados del siglo XIX se construyeron varias baterías costeras en los municipios de Aguadilla, Arecibo y Fajardo y en febrero de 1887 el ingeniero Enrique Gadea proyectó la construcción de un faro en la Punta de Bonriquen, en el municipio de Aguadilla, situado a unos 130 kilómetros al oeste de la capital, con el fin de reforzar la defensa de la costa norte de la isla, ya

${ }^{16}$ Varios documentos del Archivo Histórico Nacional certifican que, el 9 de julio de 1873, Gadea solicitó permiso para desplazarse a Puerto Rico como jefe de Obras Públicas, con el grado de ingeniero segundo de Caminos, Canales y Puertos, un sueldo de 6.000 pesetas y un sobresueldo de 4.000, aunque no llegó a San Juan hasta el 25 de noviembre de 1875, acompañado de su ayudante Ángel Aragonés. Durante su estancia en la isla proyectó la construcción de los faros de Cabezas de San Juan y los Morrillos de Cabo Rojo y planteó la necesidad de instalar un semáforo en el castillo de San Felipe del Morro. El 21 de enero de 1882 solicitó seis meses de licencia para regresar a la Península, embarcó el 14 de mayo a bordo del navío Gijón y fue sustituido por el ingeniero de primera clase Manuel Maese Peña. Hizo escala en La Habana y regresó a Cádiz en el vapor correo Antonio López el 25 de enero de 1883. El último dato que conocemos es que regresó a Puerto Rico el 1 de marzo de ese mismo año para hacerse cargo de la jefatura de Obras Públicas. Varios ingenieros pasan de la península a trabajar en la isla, AHN, Ultramar, 425, exp. 22. Expediente personal de Enrique Gadea y Villadervó, AHN, Ultramar, 6317, exp. 20. Proyecto de faro para Cabezas de San Juan de Enrique Gadea, AHN, Ultramar, 409, exp. 19. Proyecto de faro en Morrillos de Cabo Rojo de Enrique Gadea, AHN, Ultramar, 409, exp. 26.

17 Nació en Pobleta de Portaceli (Valencia) el 30 de noviembre de 1854, fruto del matrimonio de Rafael Rávena Cubello y Francisca Clavero y Badino. Ingresó en la Academia de Ingenieros procedente de la clase de paisano (10 de enero de 1876), donde fue ascendido a alférez (22 de mayo de 1878). Trabajó en la Comandancia de Subinspección de Castilla La Nueva, Madrid y Guadalajara, labor por la que fue recompensado con el grado de capitán (9 de marzo de 1883). Desconocemos la fecha exacta de su llegada a Puerto Rico, aunque podemos confirmar su presencia en la ciudad de San Juan entre 1884 y 1892. El 7 de mayo de 1892 fue destinado a las islas Filipinas para encargarse de la comandancia de ingenieros de Cavite y Manila, donde permaneció hasta el 29 de octubre de 1895 cuando regresó a Puerto Rico para dirigir la comandancia de ingenieros de telégrafos, hasta que finalmente regresó a la Península el 24 de octubre de 1898 para continuar desarrollando su carrera profesional. Hoja de servicios militares de Rafael Rávena. Archivo General Militar de Segovia, Segovia (AGMS), sig. 1. a/R-25. Ingenieros solicitan destino en servicio de obras públicas, AHN, Ultramar, 352, exp. 17. Desembarco del vapor Santo Domingo en Puerto Rico, Archivo General Militar de Madrid, Madrid, (AGMM), Archidoc, sig. 5148.43. 
que las condiciones orografías del puerto lo convirtieron en escala de los navíos procedentes de España que viajaban a México, el istmo de Panamá y Cartagena de Indias. Gadea acompañó el proyecto de un pliego de condiciones facultativas, desconocido hasta la fecha, varios planos y un presupuesto valorado en $22.474,13$ pesos. Fue construido siguiendo el modelo empleado en el faro de Maunabo, levantado en el sur de Puerto Rico: ambas edificaciones sólo se diferenciaban en el color de su fábrica. Se ha podido documentar que comenzó a construirse el 1 de diciembre de 1891, aunque no se puso en funcionamiento hasta dos años después ${ }^{18}$. El historiador puertorriqueño Mari Mut afirma que este faro contaba con una torre octogonal de casi 14 metros de alto construida en el punto central del edificio y que el gobierno norteamericano solicitó fondos para derribarlo en 1911 y reemplazarlo por otro erigido en Punta Gorda, por considerar que el faro primitivo fue construido en un emplazamiento poco visible desde la costa noreste de la isla. Afirma que este nuevo faro fue edificado siete años después a una milla de distancia al noreste del primero y a más de 61 metros sobre el nivel del mar, aunque no hemos podido localizar hasta el momento ninguna fuente documental que nos permita constatar dicha información. Sin embargo, varios informes localizados en el Archivo Histórico Nacional, permiten contestar que estuvo dotado de una torre cilíndrica de 18 metros de alto, una lámpara situada a 89 metros sobre el nivel del mar y una lente de $3 .^{\circ}$ orden fabricada por la compañía Macbeth en Nueva York. Proyectaba una luz a 18 millas de distancia y fue sustituida por un par de luces más adecuadas al tráfico aéreo en 1945, momento en el que dicho faro formó parte de la Base Ramey de la Fuerza Armada norteamericana y fue automatizado en $1976^{19}$.

Otro informe custodiado en el mismo archivo, muestra que el 17 de febrero de 1892 José María Sáinz y Ramírez ${ }^{20}$, ingeniero primero de Obras Públi-

${ }^{18}$ Sánchez Terry afirma que el faro dejó de prestar servicio en 1950 y en 1992 su fábrica estaba prácticamente arruinada como consecuencia de varios terremotos. Sobre la construcción y reparación del faro de Borinquén, AHN, Ultramar, 411, exp. 10 y 11. Sánchez Terry, 1992: 224.

${ }_{19}$ Mari Mut, s/f: 16.

${ }^{20}$ Fue destinado a Puerto Rico para reemplazar al ingeniero de primera clase Joaquín Gisbert de Antequera tras su regreso a la Península el 25 de abril de 1891. Embarcó en Cádiz a bordo del vapor Alfonso XII (30 de abril de 1891), con un sueldo de 1.200 pesos y 1.300 de sobresueldo. Durante su estancia en Puerto Rico proyectó la construcción del faro de Los Morrillos de Arecibo, la carretera n. ${ }^{\circ} 2$ que unía el municipio de Cataño y el puente de los Reyes Católicos, otra carretera que comunicaba Bayamón con la Carretera Central y una tercera entre Arecibo y Ponce pasando por Utuado y Adjuntas; aprobó la construcción de una línea de ferrocarril que unía la capital con Arecibo y proyectó la construcción de dos puentes metálicos: uno sobre el río Guajataca en el municipio de Quebradillas y el puente de Isabel II sobre el río Estero en la carretera que unía Mayagüez con el puente Peñuela, labor por la 
cas, planteó la necesidad de construir un faro de $3 .^{\circ}$ orden en la punta Morrillos consignado Morrillos de Arecibo, situado a 80 kilómetros al noroeste de la capital. Fue proyectado por Miguel Martínez Campos en el proyecto de alumbrado original, para servir de baliza de la costa situada entre los faros de Punta de Borinquén y el castillo de San Felipe del Morro. Este proyecto fue acompañado de una memoria descriptiva, varios planos que muestran el emplazamiento, planta, alzados, cortes del edificio y la torre - que no han sido localizados hasta el momento en ninguno de los archivos españoles y puertorriqueños consultados para este estudio-, algunos dibujos del torreón, la linterna y detalles de las obras de carpintería, aljibe, cañerías y atarjeas del edificio, además de un pliego de condiciones facultativas y un presupuesto valorado en $16.639,18$ pesos, documentación inédita que no ha sido mencionada por ninguno de los autores que trataron el tema ${ }^{21}$.

Varios documentos localizados en el Archivo Histórico Nacional desconocidos hasta la fecha, confirman que el 2 de enero de 1846 el castillo de San Felipe del Morro contaba con un faro construido, para iluminar la costa y evitar posibles asaltos, por Dudham (Nueva York), al igual que el em-

que fue recompensado con 1.000 pesos. El 10 de mayo de 1895 solicitó cuatro meses de licencia para restablecer su salud, aunque es posible pensar que no abandonara la isla, ya que fue nombrado ingeniero primero y director de Obras Públicas de Puerto Rico (28 de marzo de 1897) e ingeniero jefe (30 de septiembre de 1897). En diciembre de ese mismo año solicitó su regreso a la Península, desembarcó en Cádiz a bordo del vapor correo Colón y solicitó su baja en Ultramar para continuar prestando servicio en la Península. Expediente personal de José María Sáinz, AHN, Ultramar, 426, exp. 2 y 3. Construcción de la sección de carretera de Bayamón al puente de los Reyes Católicos, AHN, Ultramar, 359, exp. 9. "Línea A 1." Sección. De San Juan a Arecibo”, AHN, Ultramar, Mapas Planos y Dibujos (MPD), 529a. "Linea A 1. 'Sección. De San Juan a Arecibo. Perfil longitudinal definitivo", AHN, Ultramar, MPD, 529b. "Línea A. 3. 'Sección. De Aguadilla a Mayagüez. Perfil longitudinal definitivo", AHN, Ultramar, MPD, 530b. "Linea A. 3. ${ }^{a}$ Sección. De Aguadilla a Mayagüez. Plano parcelario”, AHN, Ultramar, MPD, 530a. Proyecto de carretera de Bayamón hasta la carretera central, AHN, Ultramar, 402, exp.1. Proyecto de la carretera Arecibo a Ponce de José M. ${ }^{a}$ Sainz, AHN, Ultramar, 401, exp. 1, 2, 3 y 4. Proyecto de puente sobre el río Guajataca por José María Sáinz, AHN, Ultramar, 404, exp.16, 17, 18 y 19. Proyecto sustituir puente de Isabel II de José M. ${ }^{a}$ Sainz, AHN, Ultramar, 404, exp. 20, 21 y 22.

${ }^{21}$ Sánchez Terrey afirma que la construcción de este faro ascendió a 29.453,90 pesos, por lo que es posible pensar que el autor no llegara a consultar el proyecto elaborado por José María Sáinz, custodiado en el Archivo Histórico Nacional. Norma Castaldi afirma que fue el último faro construido por la Corona en la isla y según Mari Mut, se puso en funcionamiento tras la Guerra Hispanoamericana hasta que se cerró en 1964. Varios actos vandálicos provocaron la destrucción de la lente y su fábrica entre 1975 y 1977, obligando al gobierno norteamericano a restaurarlo en el 2011 y actualmente es un lugar de interés turístico. Proyecto de faro en Los Morrillos de Arecibo, AHN, Ultramar, 412, exp. 7 y 11. Sánchez Terry, 1992: 233. Castaldi, 2013: 158. Mari Mut, s/f: 20. 
plazado en la ciudad de Santiago de Cuba, valorado en $8.887,78$ pesos. Su mantenimiento se estimó en $1.088,50$ pesos y fue costeado por la Junta de Comercio. Fue construido en el baluarte de Austria por ser el más cercano a la bahía, aunque más tarde fue traslado al bastión de Ochoa por ser el más cercano al mar. Contaba con una torre octogonal de hierro edificada sobre una base de ladrillo, dotada de una linterna de cinco lámparas y cinco reflectores parabólicos y una lente Fresnel que se puso en funcionamiento por primera vez el 1 de febrero de ese mismo año, convirtiéndose en el primer faro en iluminar las costas puertorriqueñas. Otro informe fechado el $10 \mathrm{de}$ septiembre de 1867 desconocido hasta la fecha, muestra que la Comisión encargada del sistema de alumbrado de la isla, propuso reemplazar el primitivo faro por uno de $3 .^{\circ}$ orden adquirido por José de Echevarría, comisionado en París, a L. Lemommier \& Cie, valorado en 17.149,62 escudos. Además, una Real Orden del 7 de marzo de 1878, confirma que se aprobó un presupuesto de $60.925,27$ pesetas para realizar varias obras de mejora en su fábrica ${ }^{22}$. Mari Mut afirma que la torre y la linterna quedaron prácticamente arruinadas durante el bombardeo norteamericano, obligando al gobierno estadounidense a reparar la base y construir sobre ella una nueva torre de hormigón dotada de una linterna y lente más moderna. En 1905 fue de nuevo reconstruida en ladrillo, dando como resultado el faro que apreciamos en la actualidad visible a 40 kilómetros de distancia de la costa, el cual fue automatizado diez años después.

\section{El SISTEMA DE ALUMBRADO DE LA COSTA ORIENTAL}

En el extremo oriental de Puerto Rico y las islas adyacentes de Vieques, Culebra y Culebrita, se hallan las Islas Vírgenes que forman parte de las Antillas Menores, un archipiélago de cincuenta islotes y cayos de reducidas dimensiones emplazados entre el océano Atlántico y el mar Caribe, habitados por franceses y dinamarqueses desde mediados del siglo XVI. Ello obligó a la administración española a construir varias obras defensivas en la isla de Vieques y llevó a la Comisión de Faros a plantear la necesidad de reforzar la defensa de Puerto Rico con la construcción de varios faros emplazados en el puerto de Fajardo, Ceiba, Vieques, Culebrita y Maunabo, para descubrir posibles desembarcos enemigos.

${ }^{22}$ Los alumnos del Cuerpo de Torreros fueron destinados a este faro, siguiendo el Reglamento de Instrucción Teórico-Práctico, redactado por el ingeniero Mariano Sichar y Salas, aprobado el 5 de noviembre de 1885 por el ingeniero jefe Enrique Gadea. 
Varios documentos localizados en el Archivo Histórico Nacional, desconocidos hasta la fecha, permiten constatar que el 10 de diciembre de 1876 Enrique Gadea proyectó la construcción del faro de 3. ${ }^{\circ}$ orden de Cabezas de San Juan en el cabo del mismo nombre, próximo al puerto de Fajardo y a las estribaciones de la cordillera de Luquillo, situado a unos 75 kilómetros al noreste de la capital, para facilitar la navegación de los navíos procedentes del nordeste de Puerto Rico, guiarlos en el espacio comprendido entre las islas de Vieques y Culebra y balizar el canal situado entre los cabos de Cabezas de San Juan y Cucarachas en el que existen abundantes arrecifes. Diseñó un edificio a 81 metros sobre el nivel del mar, con planta rectangular de 30 x 12,4 metros y cubierta de azotea, una torre cilíndrica adosada a la fachada noreste y dos crujías longitudinales y transversales dotadas de un almacén, gabinete del ingeniero, sala común o vestíbulo, cocina y dos o tres estancias para cada torrero. Proyecto que acompañó de un presupuesto valorado en 142.371,2 pesetas, cuyas obras fueron aprobadas por la Corona el 21 de diciembre del año siguiente ${ }^{23}$. Fue el segundo faro más antiguo de la isla después del faro del castillo de San Felipe del Morro. Se iluminó con una luz blanca con destellos cada tres minutos y un alcance fotométrico de 18 millas, cuya vigilancia y mantenimiento fueron realizados por dos torreros y cuyo aparato, linterna y lámpara fueron adquiridos por José Echevarría a L. Lautter, Lemommier \& Cie por 27.936,70 pesetas ${ }^{24}$. Varias fuentes documentales certifican que su construcción se prolongó hasta el 17 de febrero de 1882, fue inaugurado el 2 de mayo de ese mismo año y se mantuvo en funcionamiento hasta el ataque norteamericano, en el que su fábrica sufrió varios daños. Algún autor anota que el huracán San Ciprián (1932) destruyó la linterna y su lámpara y que en 1975 los terrenos adyacentes al edificio fueron adquiridos por el Fideicomiso de Conservación de Puerto Rico ${ }^{25}$. En 1981 este faro fue inscrito en el Registro Nacional de Lugares Históricos y a finales de esta centuria fue restaurado por Francisco Javier Blanco, director del Fideicomiso de Conservación y Beatriz del Cueto, arquitecta especializada en Conservación Histórica ${ }^{26}$. Actualmente el faro es propiedad de United State's Coast Guard, alberga una sala de exposiciones y forma parte de la Reserva Natural de Cabezas de San Juan, un área de gran

${ }^{23}$ Proyecto de faro para Cabezas de San Juan de Enrique Gadea, AHN, Ultramar, 409, exp. 19. Sobre la construcción de faro en Cabezas de San Juan, AHN, Ultramar, 409, exp. 20 y 21. Liquidación de obras del faro de Cabezas de San Juan, AHN, Ultramar, 410, exp. 4.

${ }^{24}$ Los primeros torreros de este faro fueron Ramón Dordal, quien falleció de malaria tres semanas después de ocupar el cargo, José Pérez Barrios y José Rodríguez Parada. Mari Mut, s/f: 42.

25 "Luz en las Cabezas de San Juan, 1882: 106. Mari Mut, s/f.

${ }^{26}$ Beatriz de Cueto, "La luz al final del viaje: el Faro de las Cabezas de San Juan”, Diario El Nuevo Día, sin fecha, https://construccionelnuevodia.com/noticia/la-luz-al-final-del-viajeel-faro-de-las-cabezas-de-san-juan/ 
valor ambiental situado a muy pocos metros de distancia de la bahía bioluminiscente de Fajardo.

En el proyecto de alumbrado redactado por Miguel Martínez Campos, se proyectó la construcción de un faro de $6 .^{\circ}$ orden en Ceiba, situado a 66 kilómetros al este de San Juan y poco menos de 8 kilómetros de Fajardo, para servir de baliza a los canales que circundan la isla debido a la abundancia de islotes y arrecifes en esta área, además de facilitar la navegación de los barcos procedentes de las islas de Vieques y Culebra. No fue construido hasta finales del siglo XIX como consecuencia de la falta de recursos y según se afirma, el edificio presentaba cierta similitud con el faro del castillo de San Felipe del Morro, ya que ambos fueron realizados en mampostería y pintados de color gris con detalles en blanco, aunque no hemos podido localizar hasta el momento documentos o gráficos que nos permita confirmar esta noticia. Según la misma fuente, el faro no entró en servicio hasta el año 1908, estuvo habitado por un torreo hasta 1931 cuando se instaló en él una antorcha de acetileno, se cerró seis años después y fue demolido en 1966, cuando fue reemplazado por una torre automática instalada a pocos metros de distancia de su fábrica.

Miguel Martínez Campos propuso reforzar la defensa de la costa oriental de Puerto Rico con un faro de $4 .^{\circ}$ orden en la isla de Culebra. Aunque no tenemos constancia de que llegara a ejecutarse puesto que varias fuentes confirman que el 20 de diciembre de 1881, la Comisión de Faros aprobó el traslado de este faro a Culebrita, un pequeño islote situado a unos 31 metros de Vieques y a 800 metros de la costa oriental de Culebra. Ambas islas son una prolongación en el mar de una de las estribaciones de la sierra de Luquillo, cuyo extremo por la parte de tierra es el cabo de Cabezas de San Juan, donde se proyectó un faro de $3 .^{\circ}$ orden. Manuel Maese Peña, ingeniero primero de Caminos Canales de Puertos ${ }^{27}$, proyectó la construcción del nuevo faro cuyas obras estimó concluidas en un plazo máximo de dos años. Proyecto que acompañó de un pliego de condiciones facultativas y un presupuesto de $19.478,47$ pesos, de los cuales $10.841,27$ serían ejecutados por contrata, $5.359,28$ pesos por administración y 3.277,93 pesos para la adquisición del aparato y linterna adquiridos por José de Echevarría en París ${ }^{28}$.

${ }^{27}$ Sustituyó al ingeniero jefe de Obras Públicas, Enrique Gadea el 14 de mayo de 1882. Desconocemos la fecha exacta de su llegada a la isla, así como cualquier otro dato acerca de su vida personal y profesional. Aunque varias fuentes gráficas y documentales localizadas en el Archivo Histórico Nacional, permiten constatar que durante su estancia en la isla construyó los faros de Morrillos de Cabo Rojo y las islas de Cardona y Culebrita. Expediente personal de Enrique Gadea y Villadervó, AHN, Ultramar, 6317, exp. 20.

${ }_{28}$ Proyecto de faro en la isla Culebrita de Manuel Maese, AHN, Ultramar, 410, exp. 6. Aprobado proyecto de faro en isla Culebrita de Manuel Maese, AHN, Ultramar, 410, exp. 14, 15 y 17. 
Proyectó un edificio de mampostería de planta rectangular con un cuerpo central de 9,10 x 5,90 metros, dotado de una torre de planta octogonal de 12 metros de alto en cuyo interior emplazó el depósito de petróleo; los extremos del edificio medían 14,70 x 5,60 metros, en uno de ellos levantó un vestíbulo, almacén y habitación del ingeniero y en el otro una sala, dos alcobas, cocina y escusado. Todas las estancias estaban comunicadas por un pasillo y al igual que el resto de los faros, dispuso una techumbre de azotea sostenida por un entramado de vigas y alfarjías.

El plan de alumbrado original determinó que el faro de Culebra debía contar con una luz blanca con eclipses cada minuto, aunque finalmente se dispuso una luz fija blanca con un alcance de 12 millas, cuyo mantenimiento estuvo a cargo de dos torreros. Sánchez Terry afirma que fue erigido el 5 de septiembre de 1882 y en su construcción trabajaron 45 operarios y que los gastos previstos por Maese Peña aumentaron debido a la necesidad de construir un muelle y un motor de vapor para facilitar el transporte y acarreo de los materiales ${ }^{29}$. El terremoto de 1896 provocó importantes desperfectos en su fábrica y Castaldi afirma que su estructura quedó prácticamente arruinada tras el temblor del 19 de marzo de 1925 y que el huracán San Ciprián, del 26 de septiembre de 1932, destruyó su lámpara. Fue cerrado en 1959 pero la Marina de Estados Unidos lo utilizó como punto de observación hasta que en 1975 fue automatizado y posteriormente restaurado (2003) a consecuencia del mal estado en el que se encontraba su fábrica debido a varios actos vandálicos ${ }^{30}$.

Figura 6. Proyecto del faro de $4 .^{\circ}$ orden de la isla CUlebrita: Hoja 3. $a$ : PLANTA, ALZADOS Y SECCIONES GENERALES DEL EDIFICIO Y TORRE

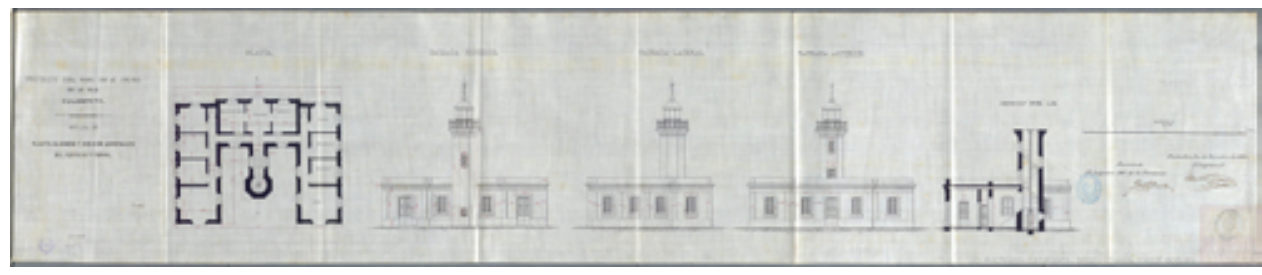

Fuente: AHN, Ultramar, MPD, 1003.

29 Según Sánchez Terry, Mari Mut y Castaldi fue inaugurado el 18 de noviembre de 1885 por los torreros Francisco Cabanellas y Luis del Olmo. Castaldi afirma, además, que la lámpara se encendió por primera vez el 25 de febrero de 1886. Sánchez Terry, 1992: 190. Castaldi, 2013: 76. Mari Mut, s/f: 39.

${ }^{30}$ Mari Mut, s/f. 
Figura 7. Proyecto del faro de $4 .^{\circ}$ orden de la isla Culebrita: HoJa 5. DETALLES DEL TORREÓN Y LINTERNA

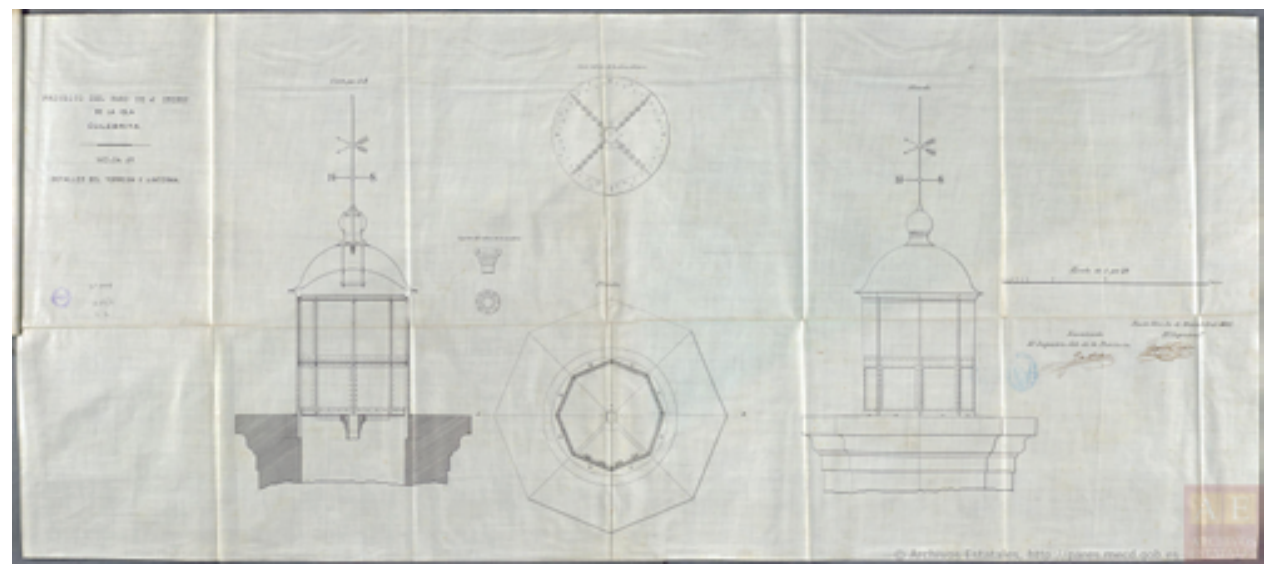

Fuente: AHN, Ultramar, MPD, 1005.

La defensa de la isla de Vieques conocida por los británicos como Vieques Crab, situada a unos 32 kilómetros al este de Fajardo y a 96 kilómetros de la capital, se reforzó a mediados de esta centuria con la construcción del fuerte de Isabel II en el municipio del mismo nombre ${ }^{31}$, durante el mandato del gobernador Rafael de Aristegui y Vélez y la edificación de varios faros según indica el proyecto de alumbrado aprobado el 2 de julio de 1890. El 19 de junio de 1893 se proyectó la construcción de un faro de $5 .^{\circ}$ orden en Punta de Mulas, un promontorio situado en la costa norte próximo al municipio de Isabel II, para facilitar la llegada de los navíos al puerto más importante de la isla. Esta propuesta fue modificada el 2 de julio del año siguiente por el ingeniero primero de Obras Públicas, Francisco de Albacete y Gil ${ }^{32}$, siguiendo el modelo emplea-

${ }^{31}$ Hinarejos Martín, 2020b: 170.

32 El 28 de octubre de1893 la Gaceta de Madrid publicó una plaza vacante de ingeniero de Obras Públicas a la que se presentaron 12 candidatos: el salmantino Ángel García García; Bienvenido Oliver y Román, de Madrid; Emilio Serrano y Navas, natural de Brunete (Madrid); Francisco Albacete Gil; Francisco Roger Cervera, natural de Valencia; Ignacio Vizcaíno Lucarella; José Casado y Rojas; José Rodríguez de Rivera; Lucio Felipe Pérez, procedente de Navarra; Marcelo Sarasola Sarasola, natural de Villafranca (Navarra); Víctor Martín Gil, nacido en Colmenar Viejo (Madrid) y Vicente Marino y Ortega. La Corona otorgó la plaza a Francisco Albacete Gil, quien embarcó en Cádiz a bordo del vapor correo Alfonso XII (30 de diciembre de 1893), con el cargo de ingeniero primero de Obras Públicas y jefe de negociado, un sueldo de 1.200 pesos y 1.800 de sobrestante. Trabajó en la isla desde el 11 de enero de 1894 hasta el 26 de mayo de 1897, cuando 
do en los faros de Guánica y Punta de las Figuras, cuyos costes estimó en $14.492,45$ pesos. Fue un edificio de mampostería de planta rectangular dotado de una sala, dos dormitorios, cocina y almacén, fachada gris y zócalo, aristones, jambas, dinteles y cornisas en blanco, una torre octogonal de 10 metros de alto y un aparato catadióptrico de luz roja fija con un alcance fotométrico de $9 \mathrm{mi}$ llas, formado por una lámpara y linterna adquiridas por José de Echevarría en París, valoradas en 3.026,63 pesos. Según indica un documento localizado en el Archivo Histórico Nacional, fue inaugurado el 1 de junio de 1896 y Normal Castaldi afirma que fue restaurado a comienzos del siglo XX. La última noticia que tenemos de este faro es que se convirtió en propiedad privada tras ser alquilado por Gilda Romero para convertirlo en su residencia a finales del siglo $\mathrm{XX}$, convirtiéndose en uno de los faros mejor conservados de la isla y actualmente pertenece a la administración municipal de Vieques ${ }^{33}$.

\section{Figura 8. Faro de $5 .^{\circ}$ orden de Puerto Ferro: HoJa n. ${ }^{\circ}$ 3: Allzados}

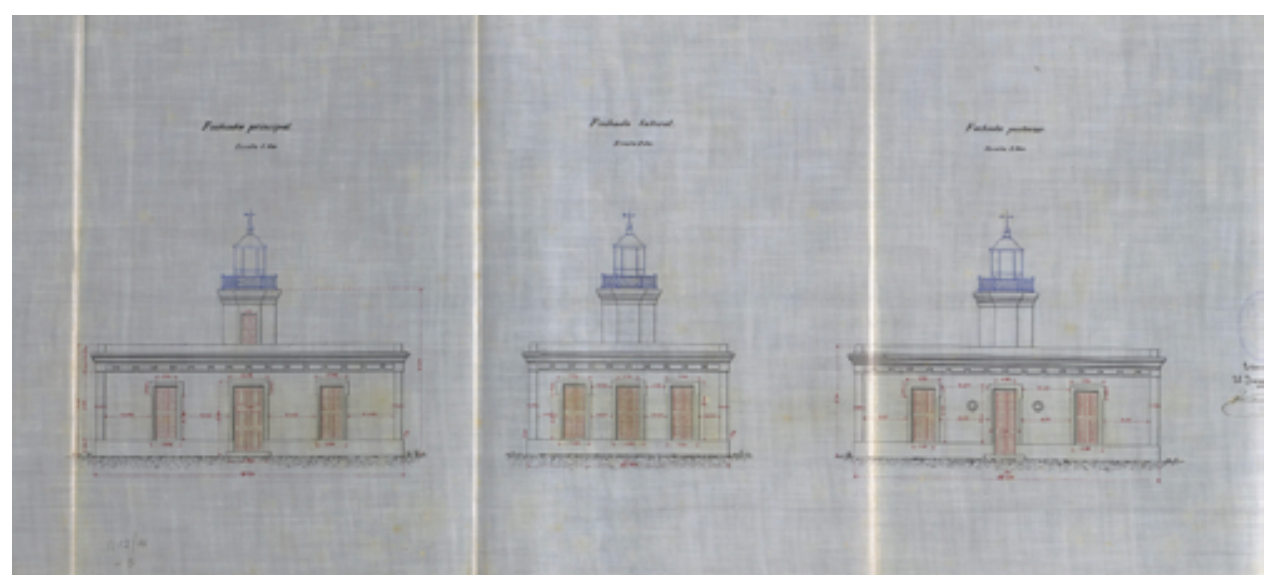

Fuente: AHN, Ultramar, MPD, 1078.

Francisco de Albacete proyectó la construcción de otro faro de $6 .^{\circ}$ orden en Puerto Ferro, situado a 8 kilómetros al sur del municipio de Isabel II, y a 14 metros sobre el nivel del mar, con costes estimados de 19.914,38 pesos,

solicitó una licencia de cuatro meses para regresar a España por motivos de salud. Expediente personal de Francisco Albacete y Gil, AHN, Ultramar, 390, exp. 38, 39, 40 y 41.

33 Aprobación de proyectos de construcción de faros en la isla de Vieques, AHN, Ultramar, 412, exp. 12. Castaldi, 2013: 148. 
para reforzar la iluminación y el balizamiento de las costas de Vieques. Fue un edificio de mampostería de planta rectangular de $16,20 \times 10,60$ metros, dividido en dos crujías dotadas de un vestíbulo, habitaciones del torrero, almacén, cocina y escusado y un aljibe de $14 \mathrm{~m}^{3}$ de capacidad y una torre con una linterna de ocho lados con montantes verticales de hierro cubiertos de bronce, cristales planos, doble cúpula de cobre, cupulino esférico con ventilación, veleta y un pararrayos con punta de platino. Sánchez Terry afirma que el gobierno norteamericano lo puso en funcionamiento tras hacerse con el poder de la isla y se mantuvo en funcionamiento hasta el año 1926.

\section{Balizamiento de la costa del CARibe}

El sistema de alumbrado y balizamiento de la costa sur limitada por el mar Caribe, se reforzó con la construcción de varios faros erigidos de este a oeste de la isla: el faro de $4 .^{\circ}$ orden de Maunabo, el de $5 .^{\circ}$ orden de Arroyo, uno de $6 .^{\circ}$ orden en Ponce, los faros de $3 .^{\circ}$ orden de la isla de Caja de Muertos y Cabo Rojo y uno de $6 .^{\circ}$ orden en isla de Mona, para facilitar la comunicación del Atlántico y el Pacífico a través del istmo de Panamá.

Un informe fechado el 16 de febrero de 1890 desconocido hasta la fecha, permite constatar que Joaquín Gisbert proyectó la construcción de un faro de $4 .^{\circ}$ orden en Punta de Tuna en el municipio de Maunabo ${ }^{34}$, situado en la costa sureste a poca distancia del cabo de Mala Pascua, siguiendo lo dispuesto por Miguel Martínez Campos en el primer plan de alumbrado de la isla ${ }^{35}$. El informe fue acompañado de una memoria descriptiva, un presupuesto valorado en 35.576 pesos y varios planos en los que aparece representada la

34 Joaquín Gisbert nació en Alcoy (Alicante), el 9 de julio de 1853. Fue hijo de Vicente Gisbert y Carbonell y Rosalía Antequera y Bobadilla. Ingresó en la Academia de Ingenieros (10 de enero de 1876) y fue ascendido a alférez (24 de diciembre de 1879) y teniente (14 de julio de 1881). Fue destinado al tercer Regimiento de Zapadores y Minadores de Cádiz y más tarde a Madrid y Puerto Real (Cádiz) hasta que el 2 de agosto de 1883 se encargó de la comandancia general de Subinspección de Ingenieros de Galicia y desde allí se desplazó a Badajoz, Cádiz y Vigo, labor por la que obtuvo el grado de capitán (12 de marzo de 1885). Dos días después fue enviado a Puerto Rico para encargarse de la comandancia de ingenieros de Obras Públicas de la isla. En 1891 solicitó permiso para regresar a la Península acompañado de su esposa y sus tres hijos, aunque no abandonó la isla hasta 1902. Hoja de servicios militares de Joaquin Gisbert Antequera, AGMS, sig. 1. a/J-770. Ingenieros solicitan destino en servicio de obras públicas, AHN, Ultramar, 352, exp. 17. Abono de pasajes a la Península para varias personas, AHN, Ultramar, 6294, exp. 5.

${ }_{35}$ Aprobado proyecto de faro en la Tuna de Joaquín Gisbert, AHN, Ultramar, 412, exp. $2,3,4$ y 5 . 
planta, alzado y perfil del edificio. Fue un edificio de mampostería de planta rectangular de 27,7 x 12,40 metros, con una torre octogonal de 13 metros de alto en el centro y una distribución interior formada por un vestíbulo, la habitación de un ingeniero, almacén, depósito de petróleo, una sala, dos alcobas, cocina y escusado. Fue construido por el contratista Adrián Duffaut entre el 15 de enero de 1891 y el 15 de julio de 1892 y se inauguró el 19 de noviembre de ese mismo año ${ }^{36}$. El edificio guardaba cierta similitud con el faro de Punta Boriquen de Aguadilla, cuya única diferencia radicaba en el color del revoco de su fábrica y en los detalles de la cornisa de la torre. Actualmente está custodiado por el Coast Guard de los Estados Unidos y es atendido por tres miembros de este cuerpo, quienes se encargan de su mantenimiento y del radiofaro situado en el mismo.

A 24 kilómetros de Maunabo y a 99 kilómetros de la capital, se construyó un faro de 5. ${ }^{\circ}$ orden en la Punta de Figuras en el municipio de Arroyo. Varias fuentes documentales localizadas en el Archivo Histórico Nacional, permiten constatar que sus costes ascendieron a 318.000 pesos, presupuesto que fue aprobado el 14 de febrero de $1892^{37}$. Fue un edificio de mampostería de color gris, de planta rectangular con una torre de 14,35 metros de alto sobre el nivel del mar, emplazada en el cuerpo central, y dotada de una linterna de planta octogonal y una luz fija blanca. Se inauguró el 16 de marzo de 1893 y varios autores afirman que fue utilizado hasta el año 1903, momento en el que quedó totalmente arruinado como consecuencia de un terremoto. El último dato que conocemos de este faro es que en 2001 se convirtió en propiedad de National Park Service, institución federal encargada de la conservación y mantenimiento de muchos edificios militares conservados en Puerto Rico.

Varios informes localizados en el Archivo Histórico Nacional, también desconocidos hasta la fecha, permiten confirmar la construcción de un faro de $6 .^{\circ}$ orden en el puerto de Ponce, debido a la presión ejercida por los comerciantes de la ciudad, que coincidieron en la necesidad de reforzar el balizamiento de la bahía para asegurar el comercio y la economía de la zona. Este faro no figura en el proyecto de alumbrado original y desconocemos la fecha exacta de su construcción, pero un informe del 1 de diciembre de 1880, certifica que el 1 de octubre de ese mismo año se encendió por primera vez una luz en Ponce. Según consta en el documento, se trataba de una lente Fresnel de 15 centímetros de distancia focal y 30 centímetros de diámetro, cerrada con una armadura de vidrio rojo y latón con orejas laterales, para ser guiada verticalmente por medio de varillas. Tenía dos lámparas y una de ellas con mecha de petróleo refinado

\footnotetext{
${ }^{36}$ Sánchez Terry, 1992: 219. Mari Mut, s/f: 52.

37 Inauguración del faro de Arroyo en Punta de las Figuras, AHN, Ultramar, 412, exp.10.
} 
conocido como brilliant ligth, al igual que el empleado en el faro de Cabezas de San Juan, cubierta con techumbre de hierro galvanizado cuyo mantenimiento era realizado por un torrero. Tras realizar un reconocimiento de su fábrica el 1 de septiembre de 1881, el ingeniero jefe de Obras Públicas, Manuel Maese, consideró que se trataba de una construcción provisional puesto que las características de su fábrica y los materiales empleados en su ejecución no eran los adecuados al clima y a las frecuentes tormentas y terremotos de la isla. Además, según consta en su informe el edificio no contaba con estancias para el alojamiento del torreo ni almacén de combustible, lo que obligó a la administración española a arrendar una vivienda particular para tal fin.

Una junta celebrada el 25 de septiembre de 1882 presidida por Martí, a la que asistieron Moreno Rocafull, Barco, Millán y el secretario Olano, aprobó la construcción de un faro en la isla de Cardona, situada a 2 kilómetros de Ponce, para señalizar la entrada y salida del puerto. Manuel Maese realizó un reconocimiento del terreno para determinar el emplazamiento adecuado, cuyas obras estimó en 11.477,22 pesos. Proyectó un edificio de mampostería de planta rectangular de 14,60 x 7,65 metros, dividido en tres crujías dotadas de sala y cocina en uno de los extremos y dormitorios en el otro y un vestíbulo, dormitorio y almacén en el cuerpo central, una torre cilíndrica de 10 metros de alto y un diámetro de 2,80 metros, adosada a uno de los lados mayores del rectángulo. El 4 de septiembre de 1886 propuso realizar varias obras de mejora, por considerar que el faro primitivo era una instalación provisional y defectuosa ${ }^{38}$. Informó de la necesidad de aumentar las dimensiones del edificio de 7,65 a 8,30 metros y dividir el interior en dos crujías, una de ellas formada por un vestíbulo, sala y dormitorio y la otra contaba con un dormitorio y cocina. Propuso, además, realizar un vestíbulo que facilitara el acceso a la torre, almacén, depósito de petróleo y escusado y dotar a estas dos últimas estancias de mayor iluminación y ventilación que la convenida por su antecesor Rafael Rávena. La construcción del nuevo faro comenzó el 1 de agosto de 1885 y se encendió por primera vez el 15 de agosto de 1889. Mari Mut afirma que este faro fue clausurado en 1950, automatizado en 1962 y actualmente es el Museo de la Guardia Costera.

Miguel Martínez Campos proyectó la construcción de un décimo faro de $3 .^{\circ}$ orden en Caja de Muertos, una isla de reducidas dimensiones y gran belleza paisajística situada a 16 kilómetros de Ponce, cuyo acceso quedó restringido al público tras ser declarada Reserva Natural el 2 de enero de 1980. Fue diseñado por Manuel Maese, quien elaboró un proyecto acompañado de varios planos, un pliego de condiciones facultativas y un presupuesto valorado en $33.975,45$

${ }^{38}$ Se aprueba el proyecto de un faro en el islote de Cardona, AHN, Ultramar, 410, exp. 1,2 y 3 . 
pesos, cuyas obras fueron aprobadas el 15 de abril de 1877. Varios planos conservados en el Archivo Histórico Nacional, permiten confirmar que se trataba de un edificio de características similares a los faros de Cabezas de San Juan, los Morrillos de Cabo Rojo y el faro de Culebrita. Fue erigido en un emplazamiento escarpado situado a 74,13 metros sobre el nivel del mar, realizado en mampostería con planta rectangular en forma de $\mathrm{H}$ formada por tres cuerpos: el central de 12,8 × 7 metros albergaba la torre, de 13 metros de alto y 2,5 metros de diámetro, dotada de una escalera en espiral de hierro forjado, un almacén, depósito de petróleo y la habitación del ingeniero. En cada uno de los laterales había una sala, dos dormitorios y una cocina. Todas las estancias estaban comunicadas por pasillos y en uno de los extremos situó la cocina y el escusado, el edificio contaba, además, con un aljibe de $4.000 \mathrm{~m}^{3}$ de capacidad. Se cubrió con una cubierta de azotea formada por dos solerías de ladrillo con cantos abiselados reforzados con dos tongadas de mortero y una de tierra y la decoración interior y exterior, según indica el ingeniero, era sobria pero elegante. Fue proyectado para ser visible a 18 millas náuticas y según indica un informe redactado por José Echavarría, el aparato, linterna y accesorios de la torre fueron adquiridos a L. Lautter, Lemommier \& Cie, al igual que el faro de la isla Culebrita, cuyos costes ascendieron a 29.665 francos. Presupuesto que fue acompañado de un pliego de condiciones facultativas y varios planos, que permiten conocer las características y detalles de la linterna y torreón, cuyos costes valoró en $7.039,34$ pesos $^{39}$. Esta misma documentación permite confirmar, que se trataba de un aparato de luz fija blanca con destellos cada tres minutos, un torreón de planta decagonal de 1,25 metros de apertura y 2 metros de alto, formado por varios montantes de hierro forjado y la parte óptica formada por cinco panales catadióptricos, cuatro catadióptricos de luz fija y tres lentes anulares intercaladas con tres paneles de luz fija. La máquina de rotación estaba provista de dos reguladores Foucault, uno de ellos de tres lámparas de movimiento de relojería, cada una de ellas provista de cuatro mecheros, dos con dos mechas para quemar aceite vegetal y otras dos de tres mechas para petróleo. El plan de alumbrado original determinó que el mantenimiento y conservación de este faro debían ser realizados por tres torreros, pero Manuel Maese consideró que dos eran suficientes, ya que esto abarataría los costes de su fábrica, puesto que de lo contrario sería necesario construir varios edificios exteriores para alojar a la familia de un torrero más ${ }^{40}$.

\footnotetext{
39 Aprobación del proyecto de establecimiento de un faro de 3er. orden en la isla Caja de Muertos, AHN, Ultramar, 410, exp. 10 y 11.

${ }^{40}$ Fue inaugurado por los torreros Severo del Olmo y César Prieto (15 de agosto de 1887), que en 1923 el sistema de iluminación se cambió de aceite y gas a electricidad y que su fá-
} 
Figura 9. Proyecto del faro de 3er orden de la isla de CAJA DE Muertos: HoJA $3^{a}$ : PLANTA, ALZADOS Y SECCIONES GENERALES DEL EDIFICIO Y TORRE

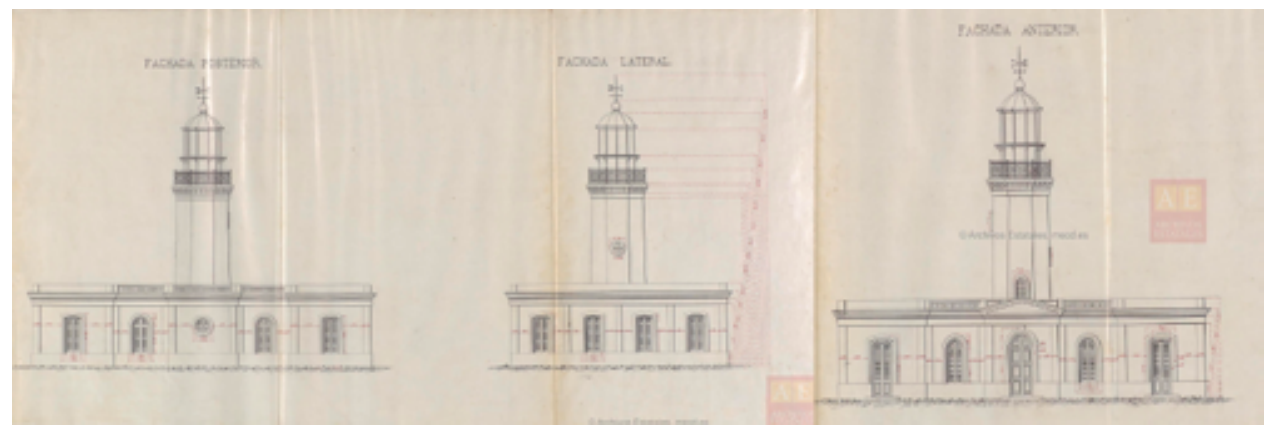

Fuente: AHN, Ultramar, MPD, 1008.

Un informe localizado en el Archivo Histórico Nacional, muestra que el 4 de febrero de 1892 José María Sáinz proyectó la construcción de un faro de $6 .^{\circ}$ orden en el puerto de Guánica, situado a 45 kilómetros al oeste de Ponce, cuyas obras estimó en 14.985,28 pesos: $12.137,77$ serían ejecutados por contrata, 1.507,01 para la adquisición de material en el extranjero y 1.340,50 para el transporte al pie de la obra, montaje, adquisición del mobiliario y utensilios necesarios ${ }^{41}$. Este informe permite asegurar que el edificio guardaba mucha similitud con el faro del mismo orden de Punta Higüero, situado a 3,4 kilómetros de Rincón. Fue un edificio de mampostería de planta rectangular, levantado a 14 metros sobre el nivel del mar, con una torre octogonal de 10 metros de alto dotada de una luz blanca fija con un alcance fotométrico de 8 millas. Desconocemos la fecha exacta de su construcción, aunque Sánchez Terry, sin apoyo documental, afirma que fue inaugurado en 1893. Convertido en cuartel durante el ataque norteamericano de 1898, en el año 2007 el ayuntamiento de Guánica y el Ministerio de Recursos Naturales y Ambientales firmaron un acuerdo para restaurar su fábrica, aunque las obras de mejora no llegaron a ejecutarse por falta de recursos económicos: actualmente, sólo se conserva parte de los cimientos y de sus parapetos ${ }^{42}$.

brica quedó prácticamente arruinada tras el huracán sufrido el 13 de septiembre de 1928 . Castaldi, 2013: 86.

${ }_{41}$ Aprueba el acta de reconocimiento de obras del faro Guánica, AHN, Ultramar, 412, exp.9.

${ }^{42}$ Robustiano Reguero fue el torrero del faro de Guánica durante el ataque norteamericano y fue testigo del desembarco de las tropas enemigas que avanzaron desde el sur hacia la capital. Castaldi, 2013: 118. 
El extremo suroeste de la isla se iluminó con un faro de $3 .^{\circ}$ orden proyectado por el ingeniero primero y jefe de Obras Públicas, Enrique Gadea, en una punta escarpada cercana a la playa de Combate y playa Sucia, de gran belleza paisajística y alto valor ecológico. El 28 de febrero de 1877 Gadea elaboró un proyecto para la construcción de un faro situado a 20 kilómetros de Cabo Rojo y 64 kilómetros al sur del faro de $6 .^{\circ}$ orden de Punta Higüero, construido entre los municipios de Aguada y Rincón. Acompañó al proyecto de un pliego de condiciones facultativas, varios planos con planta, alzado y perfil del edificio y un presupuesto detallado en pesetas: 93.038,35 de las obras que debían ejecutarse por contrata, 30.648,41 para la iluminación del faro y $8.819,54$ por administración; ascendiendo en total a 132.506,30 pesetas, 9.864,72 menos que el presupuesto del faro de Cabezas de San Juan, cuyas obras fueron aprobadas el 27 de agosto de $1880^{43}$.

Este informe permite constatar que fue el $3 .^{\circ}$ faro construido en la isla ya que se ejecutó una vez concluidas las obras del faro de Cabezas de San Juan y fuera consignado los Morrillos de Cabo Rojo. Ambos faros presentan mucha similitud en cuanto a su emplazamiento, orden y materiales y sólo se diferenciaron en el color del revoco de la fachada. Gadea proyectó un edificio de planta rectangular de 27,60 x 11,50, dividido en dos crujías longitudinales y dos trasversales de 4,70 metros de ancho, dotado de vestíbulo, salas, cocinas, dormitorios y comunes de los torreros, gabinete del ingeniero, almacén y pasillos. Diseñó una torre octogonal adosada a la parte posterior del edificio, erigida sobre un zócalo de 2 metros de alto y con una altura total de 12,50 metros, iluminada con dos vanos hacia el mar y otro hacia tierra y dotada de una escalera de hierro fundido que permitía el acceso al depósito de petróleo cubierto con una bóveda esférica. El proyecto de alumbrado planteado por Miguel Martínez Campos en 1869 , dispuso el empleo de una lente de $3 .^{\circ}$ orden y un aparato de luz blanca con eclipses por minuto, pero Gadea propuso colocar el mismo aparato que el establecido en el faro del castillo de San Felipe del Morro, formado por una parte catóptrica inferior y otra catóptrica superior fijas y una catadióptrica central

${ }^{43}$ El 20 de enero de 1881 José de Echevarría envió a la Península un informe en el que da cuenta de haber solicitado un presupuesto a tres fabricantes franceses para la adquisición del aparato de iluminación, linterna, tambor para cubrir la escalera, un fumívoro de repuesto, un nivel circular, dos depósito de seguridad para el petróleo con su pie y aceitera y algunos accesorios necesarios para los faros de Cabezas de San Juan y los Morrillos de Cabo Rojo. Los fabricantes eran Henry-Peante, L. Lautter, Lemommier \& Cie y Barbier y Tenetre, que dieron sus correspondientes presupuestos de 29.864 francos, 26.750 francos y 24.750 francos, respectivamente. El 22 de abril de ese mismo año formalizó el contrato con L. Lautter, Lemommier \& Cie. Proyecto de faro en Morrillos de Cabo Rojo de Enrique Gadea, AHN, U1tramar, 409, exp. 26, 28 y 29. 
móvil formada por ocho lentes escalonadas, una linterna con dos filas de cristales, ocho o diez montantes. Se remataba con una cúpula rematada con una bola para servir de base a la veleta; un pararrayos y tres lámparas de petróleo, por considerar que era de mejor calidad que los aceites vegetales. Dando como resultado un faro con un alcance fotométrico de 18 millas en un círculo limitado al oeste por la ensenada de Añasco y al sur por la punta Baquero, cuya finalidad era facilitar la recalada de las embarcaciones próximas a la costa, proteger los navíos que partían del puerto de Mayagüez y evitar posibles naufragios a las embarcaciones europeas. En cuanto al mobiliario el ingeniero dispuso que fuera sencillo, económico y lo estrictamente indispensable para que los torreros pudieran alojarse con el decoro y decencia necesaria. Respecto al número de empleados, consideró suficiente la presencia de dos torreros para cubrir el servicio sin riesgo de interrupción y no tres como establecía el Reglamento de Faros, por considerar este número excesivo debido a las buenas comunicaciones del faro con las poblaciones más cercanas ${ }^{44}$. Entró en funcionamiento el 20 de agosto de 1882 y en la última década del siglo XX se realizaron varias obras de mejora y reparación en su fábrica, para paliar el estado de abandono que presentaba. Norma Castaldi afirma que su maquinaria fue reemplazada por una más moderna en 1902 y según Mari Mut fue automatizado en 1967. El 22 de octubre de 1981 fue inscrito en el Registro Nacional de Monumentos Históricos del Departamento de Interior de Estados Unidos y el 24 de febrero de 1981 se convirtió en propiedad municipal debido a su valor histórico y patrimonial.

El último faro del que tenemos constancia en este sector, fue el faro de $2 .^{\circ}$ orden proyectado por Rafael de Rávena el 5 de julio de 1885 en la isla de Mona $^{45}$, situada en el canal del mismo nombre que separa las islas de Puerto Rico y República Dominicana, para facilitar la navegación de los buques procedentes de Cuba, México y Santo Domingo. El informe fue acompañado de un pliegue de condiciones facultativas y un presupuesto valorado en 101.572,88 pesos, que fue aprobado por el ingeniero jefe de Obras Públicas, Enrique Gadea, y la Comisión de Faros ${ }^{46}$. Rávena proyectó la construcción de un faro de planta rectangular sobre una punta escarpada a 68 metros sobre el nivel del mar, dotado de una torre hexagonal de hormigón hidráulico de $15 \mathrm{x}$ 2,5 metros. L. Lautter, Lemommier \& Cie suministró tres lámparas de con-

${ }^{44}$ Los primeros torreros de este faro fueron José Pérez Barrios y Eugenio Fios. El sueldo del torrero principal en 1911 era de 500 dólares y 480 el del auxiliar. Castaldi, 2013: 67. Mari Mut, s/f: 28.

${ }^{45} \mathrm{La}$ isla de Mona fue declarada Bosque Insular por el gobierno federal en 1919 y el 22 de octubre de 1981 el faro se convirtió en Monumento Histórico por el Registro Nacional de Edificios Históricos.

${ }^{46}$ Proyecto de faro en la isla Mona del ingeniero Rafael Rávena, AHN, Ultramar, 411, exp. 1. 
trapeso y una lente Fresnel que emitía una luz fija blanca con destellos cada tres minutos, capaz de iluminar una distancia de 22 millas fotométricas, cuyo mantenimiento sería realizado por tres torreros.

\section{Figura 10. FARO DE CABO ROJO}

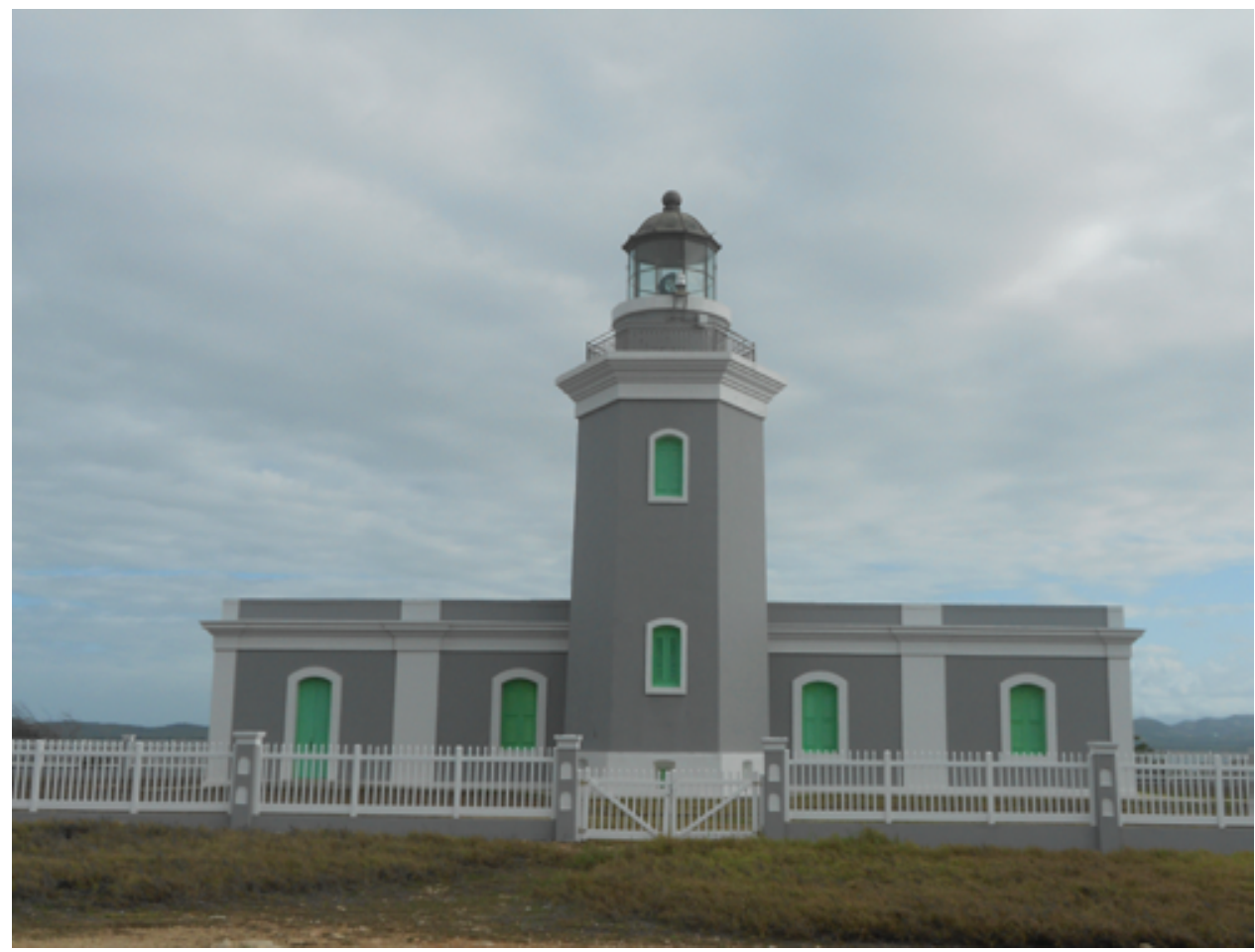

Norma Castaldi afirma sin ningún apoyo documental, que la torre fue diseñada por el arquitecto francés Gustave Eiffel y exhibida en la Exposición Universal de París de 1889 antes de ser enviada a Puerto Rico, pero no hemos podido localizar ninguna fuente gráfica ni documental que nos permita constatar esta información. La misma autora indica, además, que el faro fue ejecutado por el gobierno norteamericano siguiendo los proyectos españoles y fue inaugurado el 30 de abril de 1900, aunque tampoco se ha podido localizar ningún documento que permita constatar esta afirmación. Según Mari Mut fue automatizado en 1973, tres años después se convirtió en propiedad del Departamento de Recursos Naturales y Ambientales y se cerró en 1981. 
El sistema de Alumbrado De la costa oeste

La costa occidental de Puerto Rico se reforzó con un faro de $6 .^{\circ}$ orden en la Punta Higüero, situado a 150 kilómetros al noroeste de la capital, por lo que es posible pensar que fuera proyectado por Miguel Martínez en 1869. Posiblemente diseñado por José María Sáinz para guiar a los barcos que navegaban por el canal de Mona, entró en funcionamiento el 17 de enero de 1893, según Mari Mut ${ }^{47}$. Al igual que el de Guánica fue un edificio de mampostería de 15,24 x 8,5 metros, con fachadas cubiertas de estuco blanco rematadas en una cornisa muy elaborada y un pretil de ladrillo, con una torre octogonal en su centro de casi 9 metros de alto dotada de una lente con un alcance fotométrico de 9 millas. Sobre la puerta de entrada se colocó el escudo del Cuerpo de Ingenieros de Caminos, Canales y Puertos. Desconocemos la fecha en la que dejó de prestar servicio, pero según indica el mismo autor, su fábrica se mantuvo en perfecto estado hasta que el terremoto de San Fermín, ocurrido el 11 de octubre de 1918, agrietó y debilitó su fábrica, obligando a reconstruir la vivienda del torrero próxima al edificio y la torre que se encontraba prácticamente arruinada. Afirma, además, que la torre fue utilizada hasta 1921 cuando su linterna fue traslada a un nuevo faro construido a comienzos del siglo XX, inaugurado el 12 de enero de 1922 y automatizado en 1933. Se convirtió en escuela y en la actualidad alberga un museo marítimo y el observatorio de la isla Desecho de las ballenas que emigran hacia el océano Atlántico.

\section{CONCLUSIÓN}

El análisis de numerosas fuentes gráficas y documentales custodiadas en el Archivo Histórico Nacional, desconocidas hasta ahora, ha permitido analizar en detalle la construcción de todos los faros financiados por la Administración española a finales del siglo XIX en Puerto Rico. Existen muy pocos estudios sobre dichas construcciones y todos ellos han sido realizados por autores puertorriqueños, quienes posiblemente no llegaron a consultar los fondos documentales custodiados en España, puesto que ninguno de ellos mencionan los planos, presupuestos y proyectos elaborados por los ingenieros civiles que trabajaron al servicio de la monarquía hispana en la construcción de este primer sistema de alumbrado.

Los proyectos enviados a la metrópoli, permiten constatar que estas construcciones fueron concebidas como balizas ópticas encargadas de facilitar el

${ }^{47}$ Mari Mut, s/f: 67. 
tráfico marítimo en sus costas y tuvieron, además, una finalidad táctico-defensiva, ya que fueron diseñados para reforzar la defensa marítima de la isla y obstaculizar la navegación de navíos enemigos puesto que su finalidad era alumbrar las costas y evitar posibles desembarcos piráticos. Además, los planos, presupuestos y pliegos de condiciones facultativas que acompañaron dichos proyectos, muestran un interesante aspecto de los trabajos realizados por los facultativos del Real Cuerpo de Ingenieros Militares y los técnicos especializados del Ministerio de Obras Públicas que trabajaron al servicio de la Administración española, con la aspiración de incorporar la isla a los avances tecnológicos del siglo decimonónico.

Aunque el objetivo principal de este artículo era analizar el sistema de alumbrado ejecutado en la isla, el estudio ha servido como punto de partida para analizar otras cuestiones no menos importantes. La investigación ha permitido ofrecer una visión renovada y actualizada acerca de la significativa labor de ingeniería realizada por los técnicos especializados que trabajaron al servicio de la Corona. Sus expedientes personales contienen una valiosa información acerca de su vida personal y profesional hasta hoy desconocida: fecha y lugar de nacimiento, formación, cargos y ascensos que obtuvieron, lugares a los que fueron destinados, relaciones profesionales y militares, etc. Esto ha llevado a la autora a plantear la necesidad de realizar un próximo estudio mucho más amplio que ayude a enriquecer la información acerca de los sistemas de alumbrado construidos por la Corona española en el Caribe hispano, con el fin de crear un análisis comparativo de los mismos.

\section{BiBLIOGRAFÍA}

Aguilar Civera, Inmaculada, El discurso del ingeniero en el siglo XIX. Aportaciones a la Historia de las Obras Públicas, Madrid, Fundación Juanelo Turriano, 2012.

Alumbrado marítimo de las costas de España en Europa y Ultramar, Madrid, Imprenta Nacional, 1856.

"Carretera n. ${ }^{\circ} 2$ de la capital a Mayagüez, montaje de un puente de hierro sobre el Río de la Plata", Revista de Obras Públicas, I/24 (Madrid, 1876): 284-287.

Castaldi, Norma, Los faros de Puerto Rico, San Juan, Instituto de Cultura Puertorriqueña, 2013.

Castro Arroyo, María de los Ángeles, Arquitectura y Urbanismo en San Juan de Puerto Rico (siglo XIX), tesis doctoral de la Universidad Complutense de Madrid, 1976. 
Churruca, Evaristo de, "Proyecto de la memoria de la barra y de encauzamiento de la mitad inferior de la Ría de Bilbao", Anales de Obras Públicas. Memorias y Documentos referentes a la ciencia del Ingeniero y al arte de las construcciones, 20 (Madrid, 1883): 6-840.

Cortés Zavala, María Teresa y Uribe Salas, José Alfredo, “Ciencia y economía del guano: la Isla Mona en Puerto Rico, siglo XIX", Memorias. Revista digital de Historia y Arqueología desde el Caribe colombiano, 22 (Colombia, 2014): 81-106.

Echevarría Elguero, José, "Isla de Puerto Rico, presupuesto del material de limpieza para el puerto de la capital”, Revista de Obras Públicas, I/17 (Madrid, 1869): 154-156.

Hinarejos Martín, Nuria, "La intervención del ingeniero Juan Francisco Mestre en el sistema de defensas de San Juan de Puerto Rico", Inmaculada Rodríguez Moya, María de los Ángeles Fernández Valle y Carme López Calderón (eds.), Iberoamérica en perspectiva artística. Transferencias culturales y devocionales, Castellón de la Plana, Universidad Jaume I, 2016: 57-72.

Hinarejos Martín, Nuria, "La construcción de baterías costeras en Puerto Rico en el siglo XIX”, Magadelna de Pazzis Pi Corrales, Ana Sanz de Bremond y Carlos Díaz Sánchez (coords), La batalla: análisis históricos y militares, Madrid, Universidad Complutense de Madrid, 2020a: 855-902.

Hinarejos Martín, Nuria, El sistema de defensas de Puerto Rico (1493-1898), Madrid, Ministerio de Defesa, 2020b.

"Historia y funciones de la Comisión de Faros", Puertos del Estado, 80 (España, diciembre 2000): 49-51.

Lugo-Viña, Wenceslao, Memoria sobre las reformas de Puerto Rico, Madrid, Imprenta de Diego Valero, 1890.

"Luz en las cabezas de San Juan", Revista de Obras Públicas, I/30 (Madrid, 1882): 106.

Mari Mut, José Antonio, Los faros de Puerto Rico, sin fecha, http:// edicionesdigitales.info/FarosPR/FarosPR/Faros.html (consultado por última vez en septiembre 2021).

“Notas Varias", Revista de Obras Públicas, I/14 (Madrid, 1868): 1717

Pumarada O’Neill, Luis, Breve historia de las obras de ingeniería de Puerto Rico, San Juan, Colegio de Ingenieros Agrimensores, 1982.

Pumarada O’Neill, Luis, Los puentes históricos de Puerto Rico, Puerto Rico, Centro de Investigación y Desarrollo de la Universidad de Puerto Rico, 1991,

Pumarada O’Neill, Luis y Castro Arroyo, María de los Ángeles, La Carretera Central: un viaje escénico a la historia de Puerto Rico, Mayagüez, Centro de Investigación y Desarrollo Recinto de Mayagüez, 1996. 
Sáenz Ridruejo, Fernando, “Ingenieros de caminos en Puerto Rico. 1866-1898”, Anuario de Estudios Atlánticos, 55 (Las Palmas de Gran Canaria, 2009): 311-342.

Sánchez Beitia, Santiago, Catálogo de los faros con valor patrimonial en España, Madrid, Ministerio de Educación Cultura y Deporte, 2017.

Sánchez Terry, Miguel Ángel, Faros Españoles de Ultramar, Madrid, Editorial Ministerio de Obras Públicas y Transporte, 1992.

Sánchez Terry, Miguel Ángel, Faros españoles del Mediterráneo, Madrid, Ministerio de Obras Públicas y Transportes, 1993.

Santiago, Carolina E., Los faros de Puerto Rico y su papel defensivo en la Invasión de 1898, tesina defendida en la Universidad de Puerto Rico, 2016.

Soler Gayá, Rafael, Siglo y medio de la Comisión de Faros, Madrid, Puertos del Estado, 2006.

Fecha de recepción: 12 de noviembre de 2019.

Fecha de aceptación: 28 de abril de 2020.

\section{The first lighting and beaconing system on the coast of Puerto Rico}

The purpose of this article is to analyse the first maritime lighting system built by the Spanish Crown at various strategic points along the coast of Puerto Rico and adjacent islands in the mid-nineteenth century, in order to safeguard and develop trade and the island economy, guarantee greater safety for navigation, reinforce the defence of the main commercial ports and avoid potential enemy landings. The study is based on the analysis of various previously unknown graphic and documentary sources held in the Archivo Histórico Nacional, which permit a detailed examination of the construction of each of the lighthouses. The paper also contributes unpublished information about the public works engineers who worked on the island during this period and to whose work historians and experts in the field of architecture have as yet not drawn attention.

Key words: Puerto Rico; Lighthouses; Defence System; nineteenth century; Port, Channel and Road Engineers. 
